Originally published as:

R. Diel, G. Loytved, A. Nienhaus, S. Castell, A. Detjen, H. Geerdes-Fenge, W. Haas, B. Hauer, B. Königstein, D. Maffei, K. Magdorf, M. Priwitzer, J.-P. Zellweger, R. Loddenkemper Neue Empfehlungen für die Umgebungsuntersuchungen bei Tuberkulose Deutsches Zentralkomitee zur Bekämpfung der Tuberkulose New Recommendations for Contact Tracing in Tuberculosis German Central Committee against Tuberculosis (2011) Pneumologie, 65 (6), pp. 359-378.

DOI: $10.1055 / \mathrm{s}-0030-1256439$

This is an author manuscript.

The definitive version is available at: http://www.thieme.de/connect/de 


\title{
Neue Empfehlungen für die Umgebungsuntersuchungen bei Tuberkulose
}

\author{
New Recommendations for Contact Tracing in Tuberculosis German Central Committee \\ against Tuberculosis
}

\section{Deutsches Zentralkomitee zur Bekämpfung der Tuberkulose}

Die Empfehlungen wurden ausgearbeitet von:

R. Diel (federführend), G. Loytved ${ }^{2}$, A. Nienhaus ${ }^{3}$, S. Castell ${ }^{1}$, A. Detjen ${ }^{4}, H$. Geerdes-Fenge ${ }^{5}$, W.

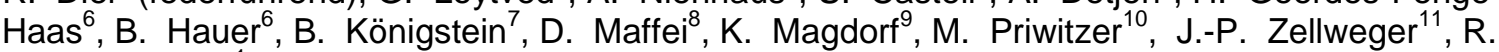
Loddenkemper $^{1}$

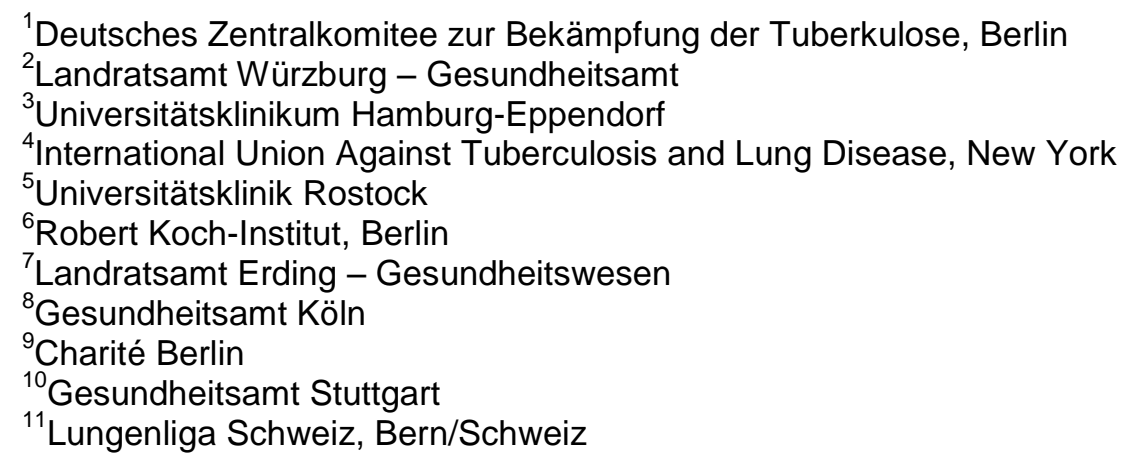

\section{Zusammenfassung}

Nach der Einführung der neuen Interferon-y-Release Assays (IGRAs) in den Empfehlungen des Deutschen Zentralkomitees zur Bekämpfung der Tuberkulose im Jahre 2007 hat sich die Datenlage für deren Einsatz beträchtlich verbessert. Da Sensitivität und Spezifität von IGRAs bei Erwachsenen in zumindest teilweise BCG-geimpften Kollektiven derjenigen des Tuberkulin-Hauttests (THT) im Allgemeinen überlegen sind, wird bei Kontaktpersonen im Gegensatz zum früheren Zweistufenverfahren nur noch der primäre Einsatz von IGRAs empfohlen. Aufgrund fehlender Evidenz über die Zuverlässigkeit von IGRAs bei Kindern unter 5 Jahren bleibt der THT in dieser Altersgruppe Mittel der Wahl; bei älteren Kindern können beide Tests angewendet werden. Die neuen Empfehlungen unterstreichen die Notwendigkeit einer sorgfältigen Vorauswahl enger Kontaktpersonen, damit positive Testbefunde mit hoher Wahrscheinlichkeit auch eine frische Infektion widerspiegeln und so den Nutzen einer Chemoprävention erhöhen. Das Nachtesten von positiv getesten Kontaktpersonen kann zu einer beträchtlichen Anzahl falsch-negativer Resultate führen und sollte bei dokumentierter Exposition daher unterbleiben.

\begin{abstract}
In 2007, the German Central Committee against Tuberculosis (DZK) published recommendations for contact tracing that introduced the new interferon gamma release assays (IGRAs). Meanwhile, substantial progress has been made in documenting the utility of IGRAs. Because IGRAs are usually superior to the tuberculin skin test (TST) in detecting latent TB infection (LTBI) with respect to sensitivity and specificity in adult contact populations that are at least partially BCG vaccinated, it is now recommended that instead of two-step testing only IGRAs be used.

As the literature does not yet provide sufficient data on the accuracy of IGRAs in children younger than 5 years, the TST remains the method of choice in that age group. To date, also, no clear body of data
\end{abstract}


exists to substantiate better performance for IGRAs than for the TST in older children, thus in this age group using of either test is recommended. The new recommendations also underscore the importance of a diligent preselection of close contacts in order to achieve a high probability that positive test results represent recent infection and to thus increase the benefit of chemopreventive treatment for those identified as requiring it. In a third point of update, it is noted that re-testing of contacts individuals found positive for LTBI may produce a considerable number of false-negative results and should thus be avoided in case of documented exposure.

\section{Glossar}

BAL: Broncho-alveoläre Lavage

BCG: Bacille Calmette-Guérin

$\mathrm{KI}$ : Konfidenzintervall

CFP-10: Culture-filtrate-protein-10

ESAT-6: Early-secreted-antigenic-target-6

IFN-Y: Interferon Gamma

IfSG: Infektionsschutzgesetz

INH: Isoniazid

LTBI: latente tuberkulöse Infektion mit Mycobacterium tuberculosis-Komplex

NTM: nicht-tuberkulöse Mykobakterien (Synonym: Umweltmykobakterien, MOTT)

NPW: negativer prädiktiver Wert

MTB: M. tuberculosis-Bakterien

P.-a.: posterior-anteriorer Strahlengang

PBMC: periphere mononukleäre Zellen

PPD: Purified-Protein-Derivative

PPW: positiv prädiktiver Wert

RFLP: restriction fragment length polymorphism

RöV: Röntgenverordnung

RR: relatives Risiko

TNF: Tumor-Nekrose-Faktor

THT: Tuberkulin-Hauttest

TRU: Thorax-Röntgen-Untersuchung

\section{Einleitung}

Die Veröffentlichung des DZK „Empfehlungen für die Umgebungsuntersuchungen bei Tuberkulose” liegt mehr als drei Jahre zurück [1]. Inzwischen wurden neue Erkenntnisse zu den In-vitro-Verfahren zur Diagnose der latenten tuberkulösen Infektion (LTBI) gewonnen. Dies und einige andere neue Gesichtspunkte machen eine Aktualisierung der bisherigen Empfehlungen erforderlich. Sie setzen neue Akzente durch

- eine zielführendere Auswahl der zu untersuchenden Kontaktpersonen durch verbesserte Risikokommunikation

- die primäre Untersuchung mit Interferon (IFN)- $y$-Tests statt dem Tuberkulin-Hauttest bei Kontaktpersonen über 15 Jahren

- eine Erweiterung der Indikationsstellung für den Einsatz von IFN- $y-T e s t s$ bei der Detektion von Personen mit LTBI auf Personen über 50 Jahre

- den Verzicht auf Nachtestungen nach abgeschlossenem Erstscreening von Kontaktpersonen mittels THT oder IFN- $y$-Tests

Die neuen Empfehlungen sollen hierdurch zur Sicherung der Qualität der nach $\S \S 25$ und 26 des Infektionsschutzgesetzes (IfSG) vorgeschriebenen Ermittlungen und Untersuchungen über Ansteckungsquelle und Ausbreitung der Tuberkulose beitragen. 


\section{Die Tuberkulose und ihre Übertragung}

\subsection{Falldefinition der Tuberkulose}

Als Tuberkulose gelten nach der Falldefinition des Robert Koch-Instituts, sofern ein Erregernachweis gelingt, Erkrankungen, die durch pathogene Bakterien des Mycobacterium (M.)-tuberculosisKomplexes (M. tuberculosis, M. bovis, M. africanum, M. microti, M. canettii und M. pinnipedii) verursacht werden. Umweltmykobakterien bzw. nicht-tuberkulöse Mykobakterien (NTM) und die verschiedenen Bacille Calmette-Guérin ( $M$. bovis BCG)-Stämme zählen nicht zu den Erregern der Tuberkulose [2].

\section{2. Übertragungsmodus der Tuberkulose}

Der Erreger M. tuberculosis wird üblicherweise direkt von Person zu Person durch aerogene Inhalation bakterienhaltigen Aerosols übertragen. Weitere mögliche Übertragungswege sind die perkutane Infektion als Schmierinfektion erregerhaltigen Materials (Urin, Abszesseiter) auf Haut- oder Schleimhautläsionen bzw. nach Inokulation durch Stichverletzung sowie die orale Infektion durch kontaminierte Milch. Während wenige Erkrankungsfälle durch Schmier- und Stichinfektionen mit Tuberkulosebakterien bei Tierärzten[2], Metzgern, Labor- und Pathologiepersonal dokumentiert sind [3], können Infektionen mit $M$. bovis auch heute noch in Gebieten der Erde durch erregerhaltige Milch übertragen werden, in denen bovine Infektionen in Rinder- und Büffelbeständen vorkommen.

\subsection{Infektionsrisiko durch den Indexfall[3]}

Die Tuberkulose zählt nicht zu den hochinfektiösen Erkrankungen. Das Risiko einer Weiterverbreitung hängt $a b$ von

- Virulenz und Menge der ausgeschiedenen Erreger

- Intensität und Dauer des Kontakts

An Lungentuberkulose Erkrankte, in deren Sputum-Direktpräparat säurefeste Stäbchen mikroskopisch nachgewiesen sind, besitzen daher die höchste Infektiosität [4]. Verglichen mit kulturell gesicherten, aber mikroskopisch negativen Lungentuberkulosen verursachen sie etwa das Fünffache an Folgefällen [5][6].

Wie viele Erreger ausgeschieden werden, wird - obwohl eine Übertragung auch beim Sprechen, Niesen, Singen und Lachen möglich ist - in erheblichem Maße vor allem von der Stärke und Häufigkeit des Hustens bestimmt [7]. Ein einziger Hustenstoß erzeugt etwa die gleiche Aerosolmenge wie 5 Minuten lauten Sprechens [8]. Kinder unter 10 Jahren kommen als Infektionsquelle in aller Regel nicht in Betracht, da sie seltener eine mikroskopisch positive Tuberkulose aufweisen, wenig oder gar nicht husten oder aber innen ein für die Erregerverbreitung erforderlicher, ausgeprägter Hustenstoß fehlt [9].

\subsection{Infektionsrisiko der Kontaktperson}

Die Wahrscheinlichkeit, sich mit Tuberkulosebakterien zu infizieren, steigt mit der Dauer des Aufenthalts in Räumen mit bakteriell kontaminierter Luft und/oder der Anzahl der Erreger pro Volumeneinheit der Luft. Eine Infektion unter freiem Himmel wie auch die Infektion infolge eines flüchtigen Kontakts in einem geschlossenen Raum ist prinzipiell möglich, aber unwahrscheinlich [10].

Als Schwellenwert der erforderlichen kumulativen Expositionsdauer für eine Infektion mit $M$. tuberculosis gilt bei einem Indexfall mit mikroskopisch offener Lungentuberkulose ein mindestens 8stündiger Raumkontakt [11] bzw. ein mindestens 40-stündiger Kontakt bei lediglich kulturellem Nachweis [12]; dies schließt Übertragungen bei kurzer, aber intensiver Exposition jedoch keinesfalls aus [13] und legt statt eines schematischen Ringprinzips [14] eine nicht nur zeit-, sondern auch 
tätigkeitsbezogene Auswahl von Kontaktpersonen nahe (s. 3.8.1).

\subsection{Erkrankungsrisiko der infizierten Person}

Da die Empfänglichkeit bzw. Verteidigungsfähigkeit (Immunstatus) der infizierten Kontaktpersonen ebenfalls eine Rolle spielt, haben Kinder, insbesondere diejenigen unter 5 Jahren [15][16], und Immuninkompetente ein höheres Erkrankungsrisiko als Menschen mit normalen Abwehrkräften. Ein besonders hohes Risiko (Relatives Risiko -RR- im Vergleich zur Allgemeinbevölkerung bzw. Tuberkulosekranke pro 1000 untersuchte Personen und Jahr in Klammern [17]) besteht z. B. für

- HIV-Infizierte (35 - 162 Tuberkulosekranke pro 1000 Personenjahre)

- i. v.-Drogenabhängige, HIV-negativ (10 Tuberkulosekranke pro 1000 Personenjahre)

- Organtransplantierte (RR 37 - 74)

- $\quad$ Silikose-Patienten (RR 30)

- Patienten mit chronischem Nierenversagen (RR 10 - 25)

- Diabetiker (RR 2 - 4)

- Gastrektomierte (RR 2 - 5)

- Personen unter Therapie mit Tumor-Nekrose-Faktor (TNF)- $\alpha$-Inhibitoren (> 5 [18]) bzw. mit Kortikoiden, Zytostatika u. ä. immunsupprimierenden Medikamenten.

\subsection{Pathogenetische Aspekte der latenten tuberkulösen Infektion bzw. der manifesten Tuberkulose}

Gelingt die Elimination der Tuberkulosebakterien nicht, so formieren sich aktivierte Makrophagen und T-Lymphozyten um die Tuberkulosebakterien zu einem von einem Fibrinmantel umschlossenen Granulom („Tuberkel”). Die Granulome der Erstinfektion liegen meist in den peripheren Lungenabschnitten, unten an der Lungenbasis und subpleural. Sie sind in der Regel so klein, dass sie dem radiologischen Nachweis entgehen. Sofern sie sich frühestens drei Wochen nach der Infektion durch Summation in einer Ebene der Röntgenaufnahme abbilden lassen, bezeichnet man sie auch als „Primärherd” [19].

Eine lymphogene Streuung der Bakterien mit vergleichbaren granulomatösen Reaktionen in den Lymphknoten ist jederzeit möglich. Primärherd und mitbeteiligter regionaler Lymphknoten werden als „Primärkomplex” bezeichnet. Tuberkulosebakterien, die direkt aus den Granulomen oder indirekt über die Lymphbahn in die Blutbahn gelangt sind, werden in apikal und dorsal gelegene Lungensegmente und andere Organe verschleppt. Fieber, Gelenkschmerzen und ein Erythema nodosum können zwar einen Hinweis auf die tuberkulöse Erstinfektion geben; zumeist verläuft die Erstinfektion jedoch asymptomatisch [20].

Solange die Erregerzahlen von der Immunantwort gering gehalten werden können, besteht lediglich eine latente tuberkulöse Infektion (LTBI). Dies kann eine lange Inkubationszeit zur Folge haben. Bei intaktem Immunsystem erkranken deshalb lediglich ca. 2 - $10 \%$ der Infizierten an einer aktiven Tuberkulose [21][22][23], wobei zwischen Erstinfektion und Krankheitsausbruch infolge ungehemmter Erregerausbreitung (Reaktivierung) Jahrzehnte liegen können. Das Risiko einer Erkrankung ist in den ersten beiden Jahren nach der Infektion, insbesondere im ersten Jahr, jedoch am höchsten [24][25].

\section{Die Umgebungsuntersuchung}

\subsection{Ziele der Umgebungsuntersuchung}

Aus epidemiologischer Sicht sind bei einer übertragbaren Krankheit folgende Aufgaben zu lösen:

- Fallfindung 
- Aufdeckung der Infektionsketten

- Verhütung der Weiterverbreitung.

An die Infektionsketten kann man aus zwei Richtungen herangehen: 1. zentripetal: Suche nach der Infektionsquelle (Quellensuche) und 2. zentrifugal: Suche nach Ansteckungsverdächtigen, Krankheitsverdächtigen und Kranken (siehe [Abb. 1]).

Bei der Tuberkulose wird beides unter dem Begriff „Umgebungsuntersuchung” zusammengefasst, ungeachtet der Unterschiede nach Ansatz, Ziel und Methodik [26].

Obwohl Reaktivierungen einer früheren tuberkulösen Erstinfektion in den westlichen Industrieländern als Ursache von Tuberkulose noch immer dominieren, haben jüngere populationsbasierte, molekularepidemiologische Studien in Europa und den USA aufgezeigt, dass auch in Ländern mit niedriger Tuberkuloseinzidenz 35 - $40 \%$ aller Fälle "frisch übertragener" Tuberkulosen

[5][27][28][29][30][31][32][33] und 13 - $16 \%$ der Wiedererkrankungen an Tuberkulose die Folge einer exogenen Reinfektion waren [34].

Hieraus folgt, dass Maßnahmen der Tuberkulosekontrolle, u. a. eine konsequente chemopräventive Therapie der LTBI, durch welche die Zirkulation von Tuberkulosebakterien wirksam eingeschränkt wird, in Deutschland, insbesondere bei Risikogruppen mit deutlich erhöhter Tuberkuloseinzidenz, zeitnah zu einer weiteren Senkung der Inzidenz führen könnten [35].

Andererseits beträgt die Quote der im Rahmen einer konventionellen Umgebungsuntersuchung entdeckten Tuberkulosefälle in großen Kohortenstudien in Niedrigprävalenzländern unter Einbeziehung von in unterschiedlichem Maße exponierten Kontaktpersonen in der Regel lediglich 1 $2 \%$ [12][24][35][37], sodass eine Fokussierung auf diejenigen Personen sinnvoll erscheint, bei deren Kontakt mit dem Indexfall nach den vorliegenden Erkenntnissen ein realistisches Infektionsrisiko mit Tuberkulosebakterien besteht (s. 3.8.1). Für Kinder, die, sofern sie infiziert wurden, besonders vulnerabel hinsichtlich einer nachfolgenden aktiven Tuberkulose sind (s. 2.5), ist die Umgebungsuntersuchung von herausragender Bedeutung: So wurden 2009 fast $50 \%$ der Tuberkulosen bei Kindern (60 von 124 Erkrankten) als Folgefälle im Rahmen von Umgebungsuntersuchungen entdeckt [35].

Mit der Entwicklung neuer In-vitro-Testverfahren (Interferon[IFN]-Y-Tests), welche sich die IFN-yProduktion sensibilisierter T-Lymphozyten zunutze machen (s. 3.5.3), haben sich nunmehr Möglichkeiten ergeben, die Treffsicherheit in der Diagnostik der LTBI zu erhöhen und die Indikation zur chemopräventiven Therapie enger stellen zu können.

\subsection{Bewertung der Ansteckungsgefahr durch den Indexfall}

Anhand der im Gesundheitsamt eingegangenen Meldung wird die Ansteckungsgefahr, die vom Indexfall ausgeht, vornehmlich basierend auf den bakteriologischen Untersuchungsergebnissen und der Organmanifestation abgeschätzt. Weitere Informationen zum klinischen Bild und Verlauf bzw. über bereits vorliegende Befunde werden eingeholt. Es wird empfohlen, bei Tuberkulose des Lungenparenchyms, Tracheobronchialbaums und Pharynx inklusive Kehlkopf

- mit mikroskopischem Nachweis säurefester Stäbchen in respiratorischen Sekreten, insbesondere im Sputum oder

- mit kulturellem oder molekularbiologischem Nachweis von M. tuberculosis-Komplex in respiratorischen Sekreten (Sputum, BAL oder Magensaft) oder

- mit Nachweis einer Kaverne im Röntgenbild, wenn das Ergebnis der mikrobiologischen Diagnostik von Sputum, BAL oder Magensaft unbekannt ist oder noch aussteht

eine Suche nach Personen einzuleiten, die sich im Kontakt mit dem Indexfall mit Tuberkulosebakterien angesteckt haben oder infolgedessen erkrankt sind (s. 3.7 bzw. 3.8).

Weiterhin wird eine Suche nach infizierten Kontaktpersonen empfohlen, 
- wenn der Indexfall als Infektionsquelle einer weiteren Erkrankung an Tuberkulose gelten kann

- wenn das Ergebnis einer Obduktion eines an Tuberkulose erkrankten Patienten Hinweise auf Ansteckungsfähigkeit zu Lebzeiten oder für eine Gefährdung des Sektionspersonals ergibt.

Von Kranken mit anderen Formen der Tuberkulose geht, selbst wenn Erreger ausgeschieden werden, in der Regel keine realistische Ansteckungsgefahr aus [38]. Zentrifugale Umgebungsuntersuchungen können dann unterbleiben und sind nur erforderlich, wenn vermutlich erregerhaltiges Material inokuliert wurde (s. 2.2). Die Frage der Quellensuche (s. 3.7) wird davon nicht berührt.

Um den Infektionszeitraum abzuschätzen, wird man den Beginn des Hustens berücksichtigen oder, wenn dies nicht möglich ist bzw. bei vorbestehendem Husten anderer Ätiologie, den Beginn der Bakterienausscheidung und damit der Infektiosität in Abhängigkeit von der Ausdehnung des Befundes 6 Monate vor Diagnosestellung, ggf. auch kürzer oder länger, annehmen.

Wenn zentrifugale Umgebungsuntersuchungen trotz Erregernachweis bei einem Fall von Lungentuberkulose unterlassen oder nur eingeschränkt durchgeführt werden, so ist dies in den Unterlagen des Indexfalles schriftlich zu begründen.

\subsection{Erfassung der Kontaktpersonen}

An Tuberkulose erkrankte Personen sind nach den $\S \S 26$ Abs. 1 und 16 Abs. 2 Infektionsschutzgesetz (IfSG) gesetzlich verpflichtet, die „erforderlichen Auskünfte” zu erteilen und exponierte Personen oder Personengruppen mit Namen und Adresse zu benennen.

Die notwendigen Ermittlungen, um Hinweise auf eine Ansteckungsquelle oder die Ausbreitung der Tuberkulose zu erhalten und eine Liste der Kontaktpersonen aufzustellen, sind jedoch nur dann Erfolg versprechend, wenn beim ersten Kontakt mit dem Tuberkulosekranken eine Atmosphäre gegenseitigen Vertrauens geschaffen und die erkrankte Person für eine Kooperation gewonnen werden kann. Erfahrungsgemäß genügt eine gesetzliche Grundlage, die den Erkrankten zur Mithilfe verpflichtet, keineswegs, um eine vertrauensvolle Mitarbeit zu initiieren.

Bereits im Erstgespräch muss daher versucht werden, durch sensible und kompetente Gesprächsführung aus dem sozialen Aktionsradius des Indexfalls schließlich diejenigen Personen und Gruppen auszuwählen, die in die Umgebungsuntersuchung einbezogen werden.

In seltenen Fällen erweisen sich Kranke als unkooperativ. Insbesondere muss in bestimmten "Szenen” und "Milieus" (z. B. bei i. v.-Drogenabhängigen, Alkoholkranken, Obdachlosen und Prostituierten) mit Ermittlungsschwierigkeiten gerechnet werden [39]. Bei Kranken, die nicht in Deutschland geboren wurden, kann die Zusammenarbeit durch Sprach- und Verständigungsschwierigkeiten, gelegentlich auch durch ein kulturell anders geprägtes Krankheitsverständnis erschwert werden. Die eingehende Aufklärung und Information des Betroffenen und seiner Angehörigen sollte daher möglichst in der jeweiligen Muttersprache (Hinzuziehung eines Dolmetschers), beispielsweise unterstützt durch die Verwendung der Informationsblätter des DZK, erfolgen.

Je nach Problemlage agieren die Mitarbeiter der Gesundheitsämter nicht nur als Bindeglied zwischen dem Erkrankten und den ihn betreuenden niedergelassenen Ärzten, sondern auch zwischen dem Erkrankten und Behörden. Anträge müssen gestellt und Wege geebnet werden ([Tab. 1]).

Oftmals ist es erst nach Bewältigung der in [Tab. 1] beispielhaft aufgeführten Probleme möglich, das eigentliche Ziel, nämlich die Erfassung der Kontaktpersonen, zu erreichen.

Um eine zielgerichtete, eingegrenzte Umgebungsuntersuchung planen zu können, sollten Verhalten und Lebensstil des Patienten in seiner vertrauten Umgebung exploriert werden. Dies ermöglicht am besten, familiäre und partnerschaftliche Bindungen sowie freundschaftliche Kontakte in Hinblick auf die Übertragung der Tuberkulosebakterien zu beurteilen.

Um die bei der Tuberkulose sehr wichtigen sozialen Aspekte zu erfassen, sollte das Gespräch mit dem Erkrankten bzw. die Erfassung der Kontaktpersonen möglichst durch Sozialarbeiter erfolgen. Es 
wird empfohlen, den Indexfall darauf hinzuweisen, dass enge Kontaktpersonen, deren Name und Adresse - sofern bekannt - dem Gesundheitsamt aus verschiedenen Gründen nicht genannt werden können, über ihr Infektionsrisiko informiert werden müssen, damit sie sich in Eigeninitiative zu den erforderlichen Untersuchungen begeben und auf Frühsymptome der Tuberkulose achten.

\subsection{Rechtliche Rahmenbedingungen}

\subsubsection{Infektionsschutzgesetz}

In der Bundesrepublik regelt das IfSG [40][41], welche Maßnahmen bei übertragbaren Krankheiten, damit auch bei der Tuberkulose, zur Prävention und Kontrolle der Erkrankung in der Bevölkerung notwendig und zulässig sind. Als Bundesgesetz genießt es Vorrang vor Landesgesetzen, z. B. vor Gesetzen des Öffentlichen Gesundheitsdienstes.

Beim Tätigwerden nach dem IfSG handelt es sich um hoheitliche Aufgaben, für die in der Regel der Öffentliche Gesundheitsdienst in Gestalt seiner Gesundheitsämter zuständig ist [42]. Die einschlägigen Regelungen finden sich in den $\S 25$ und 26 in Verbindung mit $\S \S 2$ und 16 IfSG [40][41]. Daneben sind folgende rechtsstaatliche Prinzipien zu beachten:

- Verhältnismäßigkeit der Mittel,

- ärztliche Schweigepflicht,

- grundgesetzlich garantierter Persönlichkeitsschutz, konkretisiert im Datenschutz.

Die $\S \S 25$ und 26 IfSG erteilen den Gesundheitsämtern einen Rahmenauftrag, verlangen jedoch nicht, dass die genannten Aufgaben von ihnen auch selbst durchgeführt werden. Das Gesundheitsamt muss aber sicherstellen, dass die notwendigen Untersuchungen zeitgerecht, durch einen fachlich kompetenten, in den Aufgaben des Gesundheitsschutzes erfahrenen Arzt und im methodisch gebotenen Ausmaß erfolgt sind. Sind diese Voraussetzungen erfüllt, so ist ausschließlich der untersuchende Arzt für das Ergebnis verantwortlich.

\subsubsection{Schweigepflicht und Datenschutz}

Das IfSG schränkt die ärztliche Schweigepflicht und den grundgesetzlich garantierten Persönlichkeitsschutz (Art. 2 Abs. 1 GG), konkretisiert im Datenschutz, ein, damit die Ziele des Infektionsschutzes erreicht werden können. Beides darf nur in dem Ausmaß verletzt werden, das unter Anlegung eines strengen Maßstabes für die Erfüllung des gesetzlichen Auftrages unvermeidbar ist.

Bei den Ermittlungen wird man sich in erster Linie an den Erkrankten (Indexfall) wenden. Sofern erforderlich, können nahe Angehörige und der Arbeitgeber bzw. der Personalchef zu den Kontaktpersonen befragt werden. Angaben über die Tuberkulose des Indexfalles sind auf das unerlässliche Minimum zu beschränken. Entsprechendes gilt für die Kommunikation unter Gesundheitsämtern.

Nach $\S 25$ Abs. 1 des IfSG hat das Gesundheitsamt die Aufgabe, die erforderlichen Ermittlungen über Ursache, Ansteckungsquelle und Ausbreitung einer übertragbaren Krankheit anzustellen, wenn sich ergibt oder anzunehmen ist, dass jemand krank, krankheitsverdächtig oder ansteckungsverdächtig ist. Für den Umgang mit den bei den Untersuchungen erhobenen personenbezogenen Daten enthält § 26 Abs. 2 Satz 4 IfSG eine besondere Datenschutzregelung. Danach dürfen die bei den Untersuchungen erhobenen personenbezogenen Daten nur für Zwecke dieses Gesetzes verarbeitet und genutzt werden. Die Nennung des Indexfalls gegenüber Kontaktpersonen ist eine Verarbeitung personenbezogener Daten. Sie ist rechtmäßig, wenn insbesondere die Voraussetzungen des $\S 25$ Abs. 1 IfSG erfüllt sind und wenn entweder Zweifel am tatsächlichen Vorliegen des angegebenen Kontaktes bestehen oder durch die Befragung des Indexfalles alleine Art bzw. Intensität des Kontaktes nicht hinreichend konkretisiert werden können (s. 3.2, 3.8.1).

Die Nennung des Indexfalls gegenüber Kontaktpersonen kann nach der Rechtsauffassung des Bundesministeriums für Gesundheit im Einzelfall nicht nur erforderlich sein, um Ursache, 
Ansteckungsquelle und Ausbreitung einer übertragbaren Krankheit aufzuklären. Sie kann vielmehr auch geboten sein, damit die vom Gesundheitsamt nach § 25 Abs. 2 IfSG zu treffenden Anordnungen hinreichend bestimmt sind und die von den Anordnungen Betroffenen ihre Rechte wahren können, so auch das den Auskunftspflichtigen nach $\S 25$ Absatz 1 i. V.m. $\S 16$ Abs. 2 Satz 4 IfSG zukommende Auskunftsverweigerungsrecht.[4]

Es wird empfohlen, das Vorgehen des Gesundheitsamtes in derartigen Fällen eingehend zu dokumentieren.

\subsubsection{Röntgenverordnung}

Bei jeder im Rahmen einer sachgerechten Ermittlung veranlassten zentripetalen wie zentrifugalen Untersuchung ist von einem individuell begründeten Tuberkuloseverdacht auszugehen. Dass er sich nur in einem Teil der Fälle bestätigt, ist dabei unerheblich. Insoweit besteht ein grundlegender Unterschied gegenüber den Untersuchungen nach § 36 Abs. 4 IfSG [40][41]: Dort gibt es nur eine Kollektivindikation, nämlich zu überprüfen, ob gegen die Aufnahme von Personen in eine bestimmte Gemeinschaftseinrichtung gesundheitliche Bedenken wegen einer etwaigen Erkrankung an ansteckungsfähiger Lungentuberkulose bestehen. Die Untersuchungen erfolgen also unter Gesichtspunkten des Infektionsschutzes und finden ihre Rechtsgrundlage im $\S 25$ Abs. 1, 1. Satz der Verordnung zum Schutz vor Röntgenstrahlen (Röntgenverordnung, RöV), der die Anwendung von Röntgenstrahlen in sonstigen durch das Gesetz vorgesehenen oder zugelassenen Fällen erlaubt.

Die ungleiche Ausgangsposition hat rechtliche Bedeutung. Die RöV verlangt in § 24, dass die Röntgenuntersuchung in Ausübung der Heilkunde[5] erfolgt und zwar nach $\S 25$ aus ärztlicher Indikation [43][44]. Beide Bedingungen sind sowohl für die zentripetale wie die zentrifugale Untersuchung erfüllt. Immer wird aus ärztlicher Indikation nach einer Erkrankung an Tuberkulose gesucht und das ist unstrittig Ausübung der Heilkunde.

Die Röntgenaufnahmen werden von Ärzten des Gesundheitsamtes fast ausschließlich gemäß § 26 IfSG veranlasst und unter Standardbedingungen (in der Regel p.-a.) zum Ausschluss einer Tuberkulose der Atmungsorgane durchgeführt.

Sofern das Gesundheitsamt noch selbst Röntgenuntersuchungen vornimmt, muss es alle Bestimmungen der RöV berücksichtigen, insbesondere $\S \S 13-15 a$ (allgemeine Schutzmaßnahmen), $\S \S 16$ - 18a (Qualitätssicherung einschließlich der Aktualisierung des Fachkundenachweises alle 5 Jahre), §§ 19 - 22 (Strahlenschutzbereich, Schutzvorkehrungen), § 23 (rechtfertigende Indikation), §§ 24 - 25 (Anwendungsgrundsätze und zur Anwendung berechtigte Personen) und § 28 (Aufzeichnungspflicht, Röntgenpass). Hinsichtlich des Strahlenrisikos wird auf die Veröffentlichung des DZK [45] verwiesen.

\subsection{Methodik der Umgebungsuntersuchung}

\subsubsection{Testtheoretische Voraussetzungen und Risikokommunikation gegenüber Kontaktpersonen}

Jede gemäß $§ 6$ des IfSG gemeldete Erkrankung an Tuberkulose stellt einen Auftrag an das zuständige Gesundheitsamt dar zu prüfen, ob und in welchem Umfang eine Umgebungsuntersuchung zur Aufdeckung der Infektionsquelle und/oder zur Verhütung von Folgefällen durch Chemoprävention/prophylaxe oder Früherkennung von Folgefällen durch radiologische Verlaufsbeobachtung infizierter Kontaktpersonen erforderlich ist. Der kontinuierliche Rückgang der Neuerkrankungen an behandlungsbedürftigen Tuberkulosen muss auch in Deutschland zu einer Anpassung der Kontrollstrategien zugunsten einer konsequenten chemopräventiven Therapie bei besonders erkrankungsgefährdeten infizierten Personen (z. B. Kinder, HIV-Infizierte, immunsuppressiv Behandelte, insbesondere bei Therapie mit TNF-a-Inhibitoren, s. 2.5) führen.

Ein gezielter Einsatz präventiver Maßnahmen ist abhängig von dem Vorhersagewert der in der Umgebungsuntersuchung eingesetzten Methode zur Erkennung einer Infektion. Dieser sog. positive 
prädiktive Wert (PPW) gibt die Wahrscheinlichkeit an, mit der bei testpositiven Kontaktpersonen auch wirklich eine LTBI vorliegt, und wird nach der folgenden Formel berechnet:

PPW $=$ Sensitivität $x$ Prävalenz/[Sensitivität $x$ Prävalenz + (1-Spezifität) $\times(1$-Prävalenz)]. Neben seinen für den jeweiligen Test charakteristischen Eigenschaften (Sensitivität und vor allem Spezifität) hängt die Höhe des PPW zum anderen von der Prävalenz der Infektion mit M. tuberculosis im untersuchten Kollektiv (,pre-test probability”) als epidemiologischem Parameter ab.

Eine hohe Sensitivität bezeichnet hierbei die Fähigkeit, möglichst viele Personen mit LTBI zu erfassen und somit möglichst wenig falsch-negative Ergebnisse beim Vorliegen einer LTBI zu erhalten. Die Spezifität gibt hingegen den Prozentsatz richtig negativer Ergebnisse bei Nichtinfizierten an.

Während sich die Sensitivität eines Screeningtests aufgrund des fehlenden Goldstandards für eine LTBI am Surrogat der Sensitivität bei bakteriologisch nachgewiesener Tuberkuloseerkrankung orientieren muss, kann die Spezifität nur an Studienpopulationen gesunder Erwachsener ohne bekannte Exposition gegenüber $M$. tuberculosis gemessen werden, bei denen - und daher kann die Auswahl nur in Niedrigprävalenzländern erfolgen - zugleich das Risiko einer zufälligen Exposition gegenüber unerkannten Tuberkulosepatienten sehr gering ist.

Die Infektionsprävalenz im untersuchten Kollektiv von Kontaktpersonen eines an ansteckungsfähiger Tuberkulose Erkrankten korreliert eng mit Dauer und Intensität des Kontaktes (3.8.1). Die Risikokommunikation zur Abschätzung von Kontaktart und -intensität nimmt im Gespräch zwischen dem Personal des Gesundheitsamtes und den durch die Information, sie seien gegenüber Tuberkulosebakterien exponiert und eventuell infiziert worden, meist verunsicherten Kontaktpersonen deshalb einen wichtigen Platz ein.

\subsubsection{Tuberkulin-Hauttest}

Diagnostisch lässt sich die durch intrakutane Applikation von Tuberkulin auslösbare verzögerte allergische Reaktion vom zellvermittelten Typ mittels des Tuberkulin-Hauttests (THT) als derzeit am besten dokumentierte Methode zum Nachweis einer LTBI nutzen.

Tuberkulin ist eine teilweise gereinigte Proteinfraktion aus Überständen von Kulturen von $M$. tuberculosis [46]. Nach der von Mendel und Mantoux beschriebenen Technik werden 2 Einheiten (Tuberculin Units, TU) RT 23-Tuberkulin des dänischen Statens Serum Instituts (= 0,04 $\mu \mathrm{g}$ Tuberkulin PPD RT 23 SSI), entsprechend 5 TU Purified Protein Derivative - Standard (PPD-S), in einem Volumen von 0,1 ml mittels einer 27G-Nadel und einer geeigneten kleinvolumigen („Tuberkulin”-) Spritze streng intrakutan an der Beugeseite des Unterarms injiziert.

Bei einer vorausgegangenen Infektion entsteht eine lokalisierte Reaktion mit Erythem und Induration, die innerhalb von 24 Stunden beginnt, ihren Höhepunkt zwischen 48 und 72 Stunden erreicht und allmählich wieder über die nächsten 1 - 2 Wochen abklingt. Der Ablesezeitpunkt sollte daher vorzugsweise nach 72 Stunden und spätestens nach einer Woche erfolgen [47]. Das Ablesen erfolgt durch Messung ausschließlich der Induration (Dokumentation in Millimetern, die Rötung bleibt unberücksichtigt) in der Querachse des Unterarms. Ungefähr 1 - $2 \%$ der Probanden mit einem positiven THT reagieren mit Bläschenbildung [48].

Der Zeitraum von der Infektion bis zum Auftreten der Reaktion auf Tuberkulin wird als „präallergische Phase" bezeichnet. Frühestens zwei, spätestens acht Wochen nach Infektion schlägt die Reaktion auf Tuberkulin von negativ nach positiv um [49][50].

In Deutschland wird ein Indurationsdurchmesser von $>5 \mathrm{~mm}$ bei engen Kontaktpersonen eines Indexfalls mit ansteckungsfähiger Lungentuberkulose als positiv betrachtet, um möglichst viele Infizierte mit der höchsten Sensitivität zu erfassen [51], wobei im Allgemeinen das Erkrankungsrisiko mit dem Indurationsdurchmesser zunimmt [52].

Aufgrund der in Tuberkulin enthaltenen kreuzreaktiven Antigene kann die Reaktion jedoch auch nach vorangegangener Infektion mit NTM oder M. bovis BCG positiv ausfallen [53]. Die Kreuzreaktivität bei 
BCG-Geimpften lässt individuell unterschiedlich über die Zeit nach. Die Stärke der Kreuzreaktion hängt u. a. vom Impfstamm ab [54] und ist bei BCG-Geimpften sehr wahrscheinlich erst bei einer Induration > $18 \mathrm{~mm}$ nicht mehr alleine auf die BCG-Impfung zurückzuführen [55].

Je geringer die Wahrscheinlichkeit einer Exposition ist und je länger diese zurückliegt, desto stärker treten die genannten Fehlermöglichkeiten der Tuberkulindiagnostik in den Vordergrund, desto häufiger ist mit einem niedrigen PPW und entsprechend seltener mit Folgefällen zu rechnen. Die „gepoolte” (aus entsprechenden Studien gemittelte) Spezifität des THT wurde im Vergleich mit IFN- - -Tests aufgrund der möglichen Kreuzreaktivität mit NTM oder nach BCG-Impfung daher lediglich mit $66 \%$ [56] bzw. weniger als $14 \%$ in nahezu vollständig BCG-geimpften Populationen, wie z. B. in Japan [57], angegeben. Bei strikter Begrenzung der einbezogenen Studien auf gesunde nicht-exponierte Probanden aus Niedriginzidenzländern war die Spezifität mit 88,7 \% [95 \% KI 84,6 - 92,0\%] allerdings deutlich höher [58].

Falsch-negative THT-Ergebnisse können neben Applikationsfehlern infolge zahlreicher Ursachen für eine abgeschwächte individuelle Immunkompetenz auftreten (s. [Tab. 2]) und sind bei Erwachsenen prinzipiell bereits ab der sechsten Lebensdekade zu erwarten [59]. 


\subsubsection{Interferon-Gamma (IFN-y)-Test}

In den vergangenen Jahren gelang auf der Basis der erfolgreichen Genomsequenzierung des $M$. tuberculosis [60] die Entwicklung von Testverfahren, die auf dem Nachweis von Interferon-Gamma (IFN- $\mathrm{Y}$ ) beruhen, welches von T-Lymphozyten sezerniert wird, die im Rahmen einer aktuellen oder früheren Infektion mit $M$. tuberculosis-Bakterien (MTB) sensibilisiert wurden. Diese Zellen werden in vitro mit spezifischen $M$. tuberculosis-Peptiden (ESAT-6, CFP-10 und TB 7.7) stimuliert, welche bei $M$. bovis BCG und den meisten nicht-tuberkulösen Mykobakterien (NTM) (außer M. kansasii, M. szulgai und $M$. marinum) fehlen [60]. Die beiden in Deutschland kommerziell erhältlichen IFN- $\gamma$-Tests (Synonym: Interferon Gamma Release Assays, kurz IGRA) basieren auf der direkten Messung der IFN- $\gamma$-Konzentration im Vollblut (QuantiFERON-TB ${ }^{\circledR}$ Gold In-Tube, Fa. Cellestis, Australien, abgekürzt QFT) bzw. der Bestimmung der Zahl IFN-y-sezernierender T-Lymphozyten aus isolierten peripheren mononukleären Zellen (PBMC) (T-SPOT.TB ${ }^{\circledR}$, Fa. Oxford-Immunotec, Großbritannien, abgekürzt TSpot). Ein Vergleich der Verfahren mit den von den Herstellern als positiv benannten Grenzwerten ist in [Tab. 3] zusammengefasst.

Wie beim THT kann mit IFN-y-Tests weder zwischen einer frischen und einer schon länger bestehenden Infektion noch zwischen einer LTBI und einer aktiven Tuberkulose unterschieden werden. Das Zeitfenster (Latenzzeit) der frühestmöglichen Nachweisbarkeit von IFN- $\gamma$ nach Exposition entspricht nach gegenwärtigem Kenntnisstand dem zeitlichen Ablauf der mit Tuberkulin messbaren Konversion (zwei bis acht Wochen) [62][63].

Zur Sensitivität der beiden kommerziell erhältlichen IFN- $\mathrm{Y}$-Tests bei der Detektion behandlungsbedürftiger Tuberkulosefälle im Vergleich mit dem THT wurden bislang (Stand: 1. 2. 2011) zwei Meta-Analysen [64][65] mit 40 bzw. 27 Studien sowie ein systematisches Review von 16 Studien zur Sensitivität ausschließlich bei HIV-Positiven [66] vorgelegt, die im Gegensatz zu früheren Meta-Analysen [56][67] ausschließlich kulturell, histopathologisch bzw. molekularbiologisch bestätigte Tuberkulosefälle einbezogen:

Die gemittelte Sensitivität des THT bei aktiver Tuberkulose belief sich unter den 1.238 in [64] einbezogenen Patienten auf 69,9 \% (95 \% KI 67,2 \% - 72,4 \%), für den QFT auf $81 \%$ (95 \% KI 78,1 $\%-83,1 \%$ ) und stieg in Industrieländern für den THT auf 71,5\% bzw. für den QFT auf 84,5\%.

Die gemittelte Sensitivität des T-Spot betrug 87,5\% (95\% KI 85,1\% - 89,6\%), in der Untergruppe der Industrieländer 88,5\%. In Studien mit direktem Vergleich der Sensitivität des T-Spot bzw. des QFT und des THT war die Sensitivität bei beiden IFN- - -Tests signifikant höher als diejenige des THT: TSpot vs. THT: $90,1 \%$ vs. $68,3 \%$ ( $p<0,0001)$ und QFT vs. THT $83,1 \%$ vs. $62,3 \%(p<0,001)$. Sester et al. [63], die nur Studien bewerteten, die gleichzeitig auch die Spezifität bei aktiver TB bestimmten, fanden eine Sensitivität des THT von $65 \%$, des QFT von 80 \% bzw. des T-Spot von $81 \%$.

Die Diskrepanz zwischen der Sensitivität des THT und IFN-y-Tests zeigt sich insbesondere bei HIVpositiven Individuen mit bestätigter Tuberkulose [66] und einer gemittelten Sensitivität von nur $43 \%$ (95 \% KI 36,8 \% - 49,8 \%) im Vergleich zu einer Sensitivität des QFT von $66 \%$ [95 \% KI 60,1 \% - 71,3 $\%$ bzw. des T-Spot von $72 \%$ (95 \% KI $60 \%$ - 81,5 \%).

Bei Kindern unter 15 Jahren mit kulturell bestätigter Tuberkulose ist die Datenlage zur Sensitivität von kommerziell verfügbaren IFN- $\gamma$-Tests im Vergleich mit dem THT, nicht zuletzt aufgrund der oft geringen Erregerdichte bei Tuberkulosen im Kleinkindalter, noch unzureichend. In sieben Studien wurden durch den THT mit einer gemittelten Sensitivität von $84,9 \%$ insgesamt 146 kulturell bestätigte Tuberkulosen bei Kindern bestätigt, 124 durch den QFT mit einer gemittelten Sensitivität von 84,6 \% bzw. 112 Tuberkulosen durch den T-Spot mit einer Sensitivität von $75 \%$ [68][69][70][71][72][73][74] (s. [Tab. 4]).

Überträgt man bei fehlendem Goldstandard die Sensitivitätswerte für aktive Tuberkulose auf die Sensitivität für die Detektion der LTBI, so ergibt sich hiernach bei Kindern angesichts einer gemittelten Sensitivität von jeweils 85 \% für THT und QFT bzw. 75 \% für den T-Spot kein signifikanter Unterschied. 
Da IFN- $\gamma$-Tests nur die Sensibilisierung gegenüber M. tuberculosis und potenziell gegenüber den drei genannten NTM anzeigen, fand sich insbesondere bei BCG-geimpften Personen, die noch keine bekannte Exposition gegenüber Tuberkulose hatten, eine höhere Spezifität der IFN- $\gamma$-Tests. Dies bedeutet, dass gegenüber dem THT keine falsch positiven Ergebnisse aufgrund einer vorherigen Impfung mit BCG und nur selten aufgrund des Kontaktes mit den häufigsten NTM auftreten. Neben einer gemittelten Spezifität für den QFT von 99, 4 \% (95\% KI 97,9 \% - 99,9\%) [58] wurde für den TSpot - bezogen auf einen Cut-off von mindestens 6 Spots - eine Spezifität von 96,9\% (95\% KI 94,2 $\%$ - 98,6 \%) [75], 98,0 \% (95 \% KI 86,8 \% - 99,9 \%) [70] bzw. 97,2 \% (95 \% KI 93,5 \% - 99,5 \%) [76] genannt.

Die IFN- $y$-Tests weisen darüber hinaus unabhängig von der Tuberkuloseinzidenz eines Landes eine bessere Korrelation mit dem Ausmaß des Kontaktes zu Kranken mit ansteckungsfähiger Tuberkulose (Nähe und Dauer) als der THT auf [58]. Applikationsfehler und Hautalterationen wie beim THT werden vermieden und der Proband muss für die Durchführung des Tests nur einmal erscheinen. Darüber hinaus tritt kein Booster-Effekt auf und die Interpretation ist objektiv und unabhängig vom Ableser.

Allerdings bedürfen IFN- $\gamma$-Tests eines qualitätsgesicherten Labors und die Vorgaben über Blutentnahme und Transport erfordern eine erprobte Logistik (Entnahme von Venenblut in speziellen Röhrchen, rascher und kältegeschützter Transport ins Labor). Bei Kindern im Vorschulalter kann die Entnahme von drei Röhrchen Venenblut zu jeweils $1 \mathrm{ml}$ Probleme aufwerfen.

Geht man von den genannten Sensitivitäts- und Spezifitätswerten für einen IFN- $\gamma$-Test, z. B. von 84,5 $\%$ bzw. $99 \%$ für den QFT, aus, so ergibt sich bei einer angenommenen Infektionsprävalenz von $20 \%$ (entsprechend der Infektionswahrscheinlichkeit bei engen Kontaktpersonen ansteckungsfähiger Indexpersonen) ein hoher PPW von 95,5\%. Das bedeutet für die betroffene Kontaktperson, dass mit hoher Wahrscheinlichkeit tatsächlich eine Infektion vorliegt, $d$. h. nur bei etwa $5 \%$ der positiv getesteten Kontaktpersonen besteht keine LTBI. Verringert sich die Prävalenz z. B. auf $5 \%$ (wie sie bei nicht-engen Kontaktpersonen eines Indexpatienten zu erwarten wäre, bei denen die Erreger lediglich in der Sputumkultur nachgewiesen wurden [62]), so würden bei unveränderten Testcharakteristika der PPW auf 82,4\% reduziert und ca. $18 \%$ der Kontaktpersonen trotz des positiven Testergebnisses fälschlicherweise als infiziert klassifiziert werden.

Bei Anwendung des THT bei Erwachsenen würde der PPW, selbst unter Annahme einer Infektionsprävalenz von $20 \%$, bei einer unterstellten Sensitivität von $71,5 \%$ und einer Spezifität von $88,7 \%[58]$ auf $61 \%$ sinken.

IFN- $\gamma$-Tests können in seltenen Fällen nicht interpretiert werden (unschlüssige Ergebnisse, „indeterminate results”) und falsch-negative Ergebnisse aufweisen, wenn die Probe keine lebenden oder stimulierbaren T-Lymphozyten enthält. Dies kann Folge eines technischen Laborfehlers (z. B. Einlagerung im Kühlschrank oder Einfrieren vor Inkubation mit resultierender Zellanergie) oder unsachgemäßen Transports sein, aber auch bei schwerer Lymphopenie und Immunsuppression vorkommen. In einer Meta-Analyse von 116 Studien betrug die gemittelte Häufigkeit unschlüssiger Ergebnisse 2,1 \% (95 \% KI 2,0 \%-2,3 \%) für den QFT bzw. 3,8 \% (95\% KI 3,5 \% - 4,2 \%) für den TSpot und bei der Untergruppe immunsupprimierter Patienten 4,4 \% (95 \% KI 3,9 \% - 5,0 \%) für den QFT bzw. 6,1 \% (95 \% KI 5,2 \% - 7,1 \%) für den T-Spot [62].

Bei einem nicht interpretierbaren IFN-y-Test, bei dem Personen nicht auf die positive Mitogenkontrolle (Stimulierbarkeit nicht-anergischer Lymphozyten durch Phytohämagglutinin) reagieren, sollte daher zunächst eine Testwiederholung an einer neuen Probe erfolgen, um eine ordnungsgemäße Ausführung sicherzustellen. Bleibt das Testergebnis erneut „unschlüssig”, ist ein Immundefekt in Betracht zu ziehen, sodass das Vorliegen einer MTB-Infektion auf diese Weise nicht beurteilt werden kann.

Längsschnittstudien zur prognostischen Bedeutung von IFN- $\gamma$-Testresultaten hinsichtlich des Risikos von unbehandelten Kontaktpersonen, eine aktive Tuberkulose zu entwickeln, sind erforderlich, um angesichts des fehlenden Goldstandards den Stellenwert der IFN- $\gamma$-Tests in der Detektion einer LTBI zu bestätigen. Vor dem Hintergrund nicht selten diskordanter THT-/IFN- - -Ergebnisse ist insbesondere die Bedeutung positiver IFN- $y$-Testresultate bei der Vorhersage einer Progression von der LTBI zur aktiven Tuberkulose zu prüfen. 
Bisher liegen fünf Progressionsstudien unter Verwendung kommerzieller IFN- - -Tests vor [77][78][79][80][81], von denen zwei Studien [77][78] HIV-Positive nachverfolgten und nur eine Kinder unter 15 Jahren einbezog [79]. Die Progressionsrate variierte je nach untersuchtem Kollektiv, Expositionsdauer und Latenz zum mutmaßlichen Infektionszeitpunkt zwischen 8,3 \% [77] und 17,3\% [80], sofern die Testung alleine oder beim Vergleich zwischen THT und IFN- $\gamma-T e s t s$ simultan, $d . h$. unabhängig vom Ergebnis des jeweils anderen Tests, durchgeführt wurde. Die Progressionsrate für den THT betrug hingegen nur 2,3\% [81] bis 3,3\% [79] bei einem Cut-off von > $5 \mathrm{~mm}$ bzw. 3,1\% [81] bis $4,8 \%$ [79] bei einem Cut-off von $>10 \mathrm{~mm}$.

Zur Abschätzung des Kosten-Nutzen-Verhältnisses bzw. der Kosteneffektivität in europäischen Niedriginzidenzländern liegen nur wenige Studien vor, die den höheren PPW durch die Nutzung der IFN- - -Tests einbeziehen: Die Ergebnisse einer Kosten-Nutzen-Studie für den QFT aus Deutschland [82] bzw. einer Kosten-Effektivitäts-Studie für den T-Spot aus der Schweiz [83] zeigten bei alleiniger Anwendung von IFN- $\gamma$-Tests im Vergleich mit der dualen Vorgehensweise (IFN- $\gamma$-Test erst nach positivem THT) für unterschiedliche Szenarien einer präventiven Chemotherapie jeweils geringere Kosten bzw. eine bessere Kosteneffektivität pro verhinderter Tuberkulose.

Überträgt man die Sensitivitätswerte für die aktive Tuberkulose auf die Sensitivität bei der Detektion der LTBI, so führt der THT als vorgeschaltetes Screening bei Erwachsenen gegenüber einem IFN- $\gamma-$ Test in einem zweistufigen Verfahren zu einer Mindererfassung von 13\%-17\% der MTB-Infizierten, welche dann der Nachtestung mit einem IFN- $y$-Test nicht mehr unterzogen würden. Aus diesem Grund wird bei Erwachsenen ab dem 15. Lebensjahr nicht mehr eine Kombination beider Testverfahren, sondern prinzipiell der routinemäßige Ersatz des THT durch IFN- $\mathrm{\gamma}$-Tests in der Umgebungsuntersuchung angeraten. Bei vorhersehbarer fehlender Akzeptanz eines THT, nach BCGImpfung bzw. bei Immunsupprimierten, bei denen eher mit einem falsch-negativen THT gerechnet werden muss (z. B. HIV-Infizierte [84][85], hämodialysierte Patienten [86] oder Patienten vor Therapie mit anti-TNF- $\alpha$-Inhibitoren [87]) ist der primäre Einsatz von IFN- $\gamma$-Tests bereits früher empfohlen worden.

Da bislang noch zu wenige IFN- $y$-Test-Studiendaten, insbesondere für das Alter von Kindern unter 5 Jahren, vorliegen, ist in dieser Altersgruppe der THT nach wie vor die Methode der ersten Wahl (s. 3.8.2.2). Angesichts bislang fehlender Evidenz kann der Einsatz eines IFN-Y-Tests bei der Umgebungsuntersuchung von solchen jungen Kontakt-Kindern lediglich zusätzlich zum THT in Betracht gezogen werden, wenn durch die Kombination beider Methoden eine maximale Sensitivität erreicht werden soll. Allerdings schließt, im Verdachtsfalle, auch dann ein negativer THT oder IGRA eine latente oder auch aktive Tuberkulose nicht gänzlich aus.

\subsubsection{Röntgenuntersuchung}

Mit der Thorax-Röntgenuntersuchung (TRU) kann, unabhängig von einer klinischen Symptomatik, bei Kleinkindern und immunsupprimierten Patienten unter Umständen noch bevor der THT oder IFN-YTest positiv ausfällt, eine aktive Tuberkulose erfasst werden. In der Regel ist zur Tuberkulosediagnostik eine p.-a.-Aufnahme ausreichend [88]. Auf Tuberkulose verdächtige Röntgenbefunde sind stets durch die bakteriologische Untersuchung dreier Sputumproben und erforderlichenfalls durch eine weitergehende Diagnostik abzuklären. Dabei hat es sich als nützlich erwiesen, gleich nach Feststellung des radiologischen Befundes ein Sofortsputum im Amt oder beim Hausbesuch zu gewinnen. Ansonsten ist der Untersuchung von Morgensputum an drei unterschiedlichen Tagen einer Woche bzw. bei Kindern eine Untersuchung des Magensaftes der Vorzug zu geben [89].

\subsection{Beratung von Kontaktpersonen}

Anlässlich der ersten anstehenden Untersuchung sollte ein Beratungsgespräch im Gesundheitsamt oder dort, wo die Kontaktperson am besten erreichbar ist, stattfinden, um

- Art, Dauer und Intensität des Kontaktes zum Indexfall zu erfahren und um so das Erfordernis weiterer Untersuchungen zu überprüfen, 
- Angaben zur Empfänglichkeit bzw. zu Risikofaktoren zu erheben, die beim Vorliegen einer LTBI deren Fortschreiten in eine behandlungsbedürftige Tuberkulose begünstigen,

- anamnestische Angaben zu BCG-Impfung, früherer Tuberkuloseerkrankung, den Ergebnissen früherer Tuberkulin-Haut- und/oder Interferon- $y$-Tests und im Hinblick auf eine eventuell später anstehende TRU über das Vorliegen einer Schwangerschaft zu erhalten,

- zu klären, ob Faktoren zu berücksichtigen sind, die zu falsch-negativen THT-Ergebnissen führen können (s. [Tab. 2]),

- $\quad$ sie zu den üblichen Symptomen der Tuberkulose (Husten oder Hüsteln, Müdigkeit, Appetitlosigkeit, Gewichtsabnahme, leichtes Fieber, Nachtschweiß, Stechen in der Brust, Blutbeimengung im Auswurf, Benommenheit und Kopfschmerzen, Lymphknotenschwellung) zu befragen und aufzuklären,

- das diagnostische Prinzip des IFN- $y$-Tests bzw. des THT (einschließlich möglicher unerwünschter Wirkungen) und der TRU p.- a., falls indiziert, zu erläutern und auf die gesetzliche Pflicht zur Duldung der genannten Untersuchungen gemäß §§ 25 Abs. 1 und 26 Abs. 2 IfSG hinzuweisen,

- das mit einer LTBI verbundene Erkrankungsrisiko und mögliche Tuberkulosesymptome selbst nach Jahren mit dem Ziel einer sensiblen Wahrnehmung erster eigener Symptome zu erklären,

- bei gegebener Indikation die Schutzwirkung einer korrekt durchgeführten Chemoprävention bzw. die Notwendigkeit einer chemoprophylaktischen Behandlung darzustellen und das Einverständnis für die Zusammenarbeit mit dem behandelnden Arzt zu erwirken.

\subsection{Zentripetale Umgebungsuntersuchung (Quellensuche)}

\subsubsection{Indikation}

Ungeachtet der Ansteckungsgefahr, nach welcher der Indexpatient kategorisiert wird, stellt sich die Frage nach seiner Ansteckungsquelle. Die Ermittlung von Infektionsquellen und deren Ausschaltung haben bei der Bekämpfung der Tuberkulose durch das Gesundheitsamt daher hohe Priorität.

Es wird empfohlen, bei folgenden Formen der Tuberkulose nach einer Infektionsquelle zu suchen, da sich diese in aller Regel relativ zeitnah im Anschluss an eine frische tuberkulöse Infektion entwickeln [20]:

- Primärtuberkulose (unmittelbare Weiterentwicklung des Primärkomplexes oder intrathorakale Lymphknoten-Tuberkulose)

- Ersterkrankung bei Kindern unter 15 Jahren

- Meningitis tuberculosa (tuberkulöse Hirnhautentzündung)

- Pleuritis tuberculosa (tuberkulöse Rippenfellentzündung)

Auch Miliartuberkulosen (hämatogene Streuungstuberkulosen) und Ersterkrankungen bei immungeschwächten Personen können Folgen einer frischen tuberkulösen Infektion sein.

Die Inkubationszeit dieser Tuberkuloseformen, bei denen man in der Regel von einer Erstinfektion ausgehen kann, variiert stark und kann mindestens 2 Wochen bis 24 Monate (oder mehr) betragen. Gesucht wird dementsprechend eine an Lungentuberkulose erkrankte Person, die bereits seit Wochen Tuberkulosebakterien ausscheidet und die als Infektionsquelle einer an Primärtuberkulose oder anderen Frühformen der Tuberkulose erkrankten Person (Indexfall der Quellensuche) in Betracht kommt. Je jünger der Indexfall und je kürzer die Inkubationszeit ist, desto größer ist die Wahrscheinlichkeit, die Infektionsquelle zu finden. Die Suche nach einer Ansteckungsquelle soll bei Indexpatienten unter 5 Jahren begonnen werden, auch wenn eine abschließende Bestätigung der Diagnose noch aussteht [90]. 
- beim Indexpatienten eine Infektion mit MTB seit längerem bekannt ist,

- eine abgeheilte Tuberkulose dokumentiert ist oder

- eine exogene Neuinfektion mit MTB anamnestisch, z. B. bei früherem Tuberkulosekontakt oder Herkunft aus einem Hochprävalenzland, unwahrscheinlich ist.

\subsubsection{Vorgehensweise}

Da Kinder unter 10 Jahren als Ansteckungsquelle nur ausnahmsweise in Frage kommen, wird empfohlen, alle Personen ab einem Alter von 10 Jahren, die in den letzten zwei bis sechs Monaten (ggf. auch länger zurückliegend) engen Kontakt zum Indexfall der Quellensuche hatten, umgehend zu einer Untersuchung aufzufordern, um eine offene Lungentuberkulose auszuschließen oder nachzuweisen.

Um die Verhältnismäßigkeit der eingesetzten Mittel zu wahren, sollte berücksichtigt werden, dass asymptomatische Verläufe von ansteckungsfähigen Tuberkulosen sehr selten sind und dass Husten der entscheidende Mechanismus zum Transport der Tuberkulosebakterien aus dem Lungenherd in die Raumluft ist.

Es wird daher empfohlen, bei symptomatischen Personen vorrangig eine einmalige TRU durchzuführen. Bei symptomatischen Schwangeren (Husten mit Auswurf) sollten obligat drei Untersuchungen des Morgensputums innerhalb einer Woche durchgeführt werden. Die Indikation zu einer TRU muss sorgfältig unter Berücksichtigung des Schwangerschaftsstadiums abgewogen werden. Der betreuende Gynäkologe ist in den Entscheidungsprozess einzubeziehen. Grundsätzlich können Schwangere auch mittels des IFN- $y$-Tests untersucht werden; im Fall respiratorischer Symptome aber schließt ein negatives Testergebnis eine manifeste Tuberkulose - ungeachtet der Schwangerschaft - keinesfalls aus. Bei einem positiven Testresultat stellt sich die Frage der Chemoprävention, sofern keine behandlungsbedürftige Tuberkulose nachgewiesen wurde (s. 3.8.2.4 und 3.8.2.5).

Für asymptomatische Kontaktpersonen, d. h. auch für Schwangere, kommt im Erwachsenenalter primär ein IFN- $\gamma$-Test, bei Kindern ein THT oder IFN- $\gamma$-Test in Betracht (s. 3.8.2.2 ff.).

Im Fall eines positiven Testergebnisses ist eine TRU p.-a. erforderlich, um eine Tuberkulose der Atmungsorgane auszuschließen.

Die Untersuchung sollte im Fall der Quellensuche bis zur Aufdeckung einer Infektionsquelle fortgesetzt werden oder bis alle angegebenen Kontaktpersonen untersucht wurden.

Werden bei der Suche nach der Ansteckungsquelle THT- bzw. IFN-y-Test-Reagenten und Konvertoren oder Ersterkrankungen, wie sie unter Punkt 3.8.2.1 aufgeführt sind, entdeckt, wird empfohlen, die Untersuchungen auf weitere Personen auszudehnen, bei denen eine ansteckungsfähige Tuberkulose vermutet wird. Im Rahmen der Anamneseerhebung sind Aufenthalte in Hochprävalenzländern ebenso zu berücksichtigen wie der Besuch ausländischer Verwandter und Bekannter.

Eine aufgespürte Ansteckungsquelle wird zu einem neuen Indexfall und damit zum Anlass für eine zentrifugale Umgebungsuntersuchung. 


\subsection{Zentrifugale Umgebungsuntersuchung}

\subsubsection{Auswahl von Kontaktpersonen}

Personen, die aufgrund ihres Kontakts zu einem an ansteckungsfähiger Tuberkulose Erkrankten (s. 2.1) ein erhöhtes Infektions- bzw. Erkrankungsrisiko haben, werden im Rahmen einer zentrifugalen Umgebungsuntersuchung ermittelt und untersucht. Da Infektions- und Erkrankungsrisiko unter anderem von Häufigkeit, Dauer und Intensität des Kontaktes abhängen, ist zwischen engen und geringen Kontakten zu unterscheiden.

Um die Risiken der Übertragung der Tuberkulosebakterien beurteilen und eine Einteilung der Kontaktpersonen in Risikogruppen vornehmen zu können, stellt das Gesundheitsamt die erforderlichen Ermittlungen gemäß $§ 25$ Abs. 1 IfSG an. Es wird empfohlen, in eine zentrifugale Umgebungsuntersuchung diejenigen Personen einzubeziehen, die während des infektiösen Stadiums, hilfsweise in den letzten zwei bis sechs Monaten vor Diagnosestellung, einen engen Kontakt zum Indexfall hatten, indem sie

- mit dem Indexfall intime Kontakte hatten oder mit inm in derselben Wohnung, im selben Zimmer (z. B. eines Heimes, eines Krankenhauses oder in derselben Zelle einer Justizvollzugsanstalt) oder sonstigen geschlossenen Räumen gelebt haben oder

- besonders intensive, auch einmalige Kontakte mit dem Indexfall in geschlossenen Räumen hatten, bei denen mangels geeigneter Schutzmaßnahmen bakterienhaltiges Aerosol eingeatmet werden konnte, wie sie vorkommen - bei engen körperlichen Kontakten (Tanzen, Kampfsportarten etc.)

- bei pflegerischen Verrichtungen (auch bei der häuslichen Versorgung) oder Atemgymnastik

- bei oraler Inspektion, zahnärztlicher oder HNO-ärztlicher Untersuchung

- bei Sputumprovokation, Absaugen des Nasen-Rachen-Raums mit offenem System, Maßnahmen der Wiederbelebung, Bronchoskopie

- bei der Obduktion oder

- mit einem an Lungentuberkulose mit mikroskopischem Nachweis säurefester Stäbchen in Sputum-Direktpräparat, in der BAL oder im Magensaft erkrankten Indexfall kumulativ insgesamt mindestens 8 Stunden in geschlossenen Räumen oder Verkehrsmitteln verbracht haben [90][91] oder

- mit einem kulturell oder molekularbiologisch gesicherten, an Lungentuberkulose ohne mikroskopischem Nachweis säurefester Stäbchen in Sputum-Direktpräparat, provoziertem Sputum, in der BAL oder im Magensaft erkrankten Indexfall insgesamt mindestens 40 Stunden in geschlossenen Räumen oder Verkehrsmitteln verbracht haben [12].

Diese Klassifizierung wurde durch eine Studie bestätigt, in der die Kontaktdauer als Einzelfaktor mit einer deutlich höheren Chance einer QFT- bzw. T-Spot-Positivität verbunden war, wenn der kumulierte Kontakt mit einem sputumnegativen Indexfall mindestens 40 Stunden betragen hatte und in welcher sich die Chance einer IFN- $\gamma$-Test-Positivität bei Kontakt mit sputumpositiven Indexpersonen ab einer Kontaktzeit von 8 Stunden mehr als verdoppelte [62].

Personen, die keines dieser vier Kriterien eines engen Kontakts erfüllen, sind nur nach sorgfältiger Prüfung eines erhöhten individuellen Erkrankungsrisikos in eine zentrifugale Umgebungsuntersuchung einzubeziehen (s. 2.5). 


\subsubsection{Vorgehensweise (Flussdiagramme in den [Abb. 2 4])}

\subsubsection{Primäre Thorax-Röntgenuntersuchung}

Bei folgenden Kontaktpersonen wird empfohlen, unverzüglich nach Stellung der Diagnose beim Indexfall primär eine TRU p.-a. zu veranlassen, um eine behandlungsbedürftige (u. U. auch ältere, nicht auf einer frischen Infektion beruhende) Tuberkulose der Thoraxorgane auszuschließen:

bei

- tuberkuloseverdächtigen Symptomen

- einer Erkrankung an Tuberkulose in der Vorgeschichte

- bekannt positivem Tuberkulin-Haut- bzw. IFN-y-Test

- Faktoren, die zu falsch-negativen Tuberkulin-Testergebnissen führen können (s. [Tab. 2]), sofern kein IFN- $y$-Test verfügbar ist.

- Personen, bei denen aufgrund ihrer Lebensumstände mit dem Nichteinhalten des Ablesetermins des THT gerechnet werden muss, sofern kein IFN-y-Test verfügbar ist.

- geplanter Einleitung einer Chemoprophylaxe (Kinder unter 5 Jahren) [92]

Für Kontaktpersonen, die mit dem an einer im Sputumausstrich oder in der BAL mikroskopisch positiven Lungentuberkulose erkrankten Indexpatienten zusammenwohnen, ist zusätzlich zum THT bzw. IFN- $y$-Test (s. 3.8.2.3 und 3.8.2.4) die Indikation zur umgehenden TRU großzügig zu stellen, weil bereits eine unter Umständen ansteckungsfähige Tuberkulose vorliegen kann und das Abwarten der Testergebnisse eine unnötige Verzögerung der Diagnose bedeuten würde. Bei radiologischen Zeichen, die mit einer Erkrankung an Tuberkulose vereinbar sind, sind weiterführende Untersuchungen zur Sicherung oder zum Ausschluss der Diagnose einer behandlungsbedürftigen Tuberkulose erforderlich [53].

\subsubsection{Kontaktpersonen unter 5 Jahren}

Nicht nur die Diagnose und Behandlung der aktiven Tuberkulose stellen im Kindesalter eine besondere Herausforderung dar, sondern auch die frühzeitige Identifikation von Kindern mit einer LTBI, bei denen der Manifestation einer Tuberkulose durch eine Chemoprävention vorgebeugt werden muss. Darüber hinaus ist bei exponierten Kindern bereits das Angehen einer tuberkulösen Infektion durch eine Chemoprophylaxe zu verhindern. Besonders im Säuglingsalter und bei Kleinkindern bis zum 5. Lebensjahr drohen durch eine frühe Generalisation der Tuberkulose schwere Erkrankungsformen wie die tuberkulöse Meningitis oder die Miliartuberkulose, die mit einer hohen Letalität einhergehen.

Es wird daher empfohlen, bei Kontaktpersonen unter 5 Jahren (von der Geburt bis zum 5. Geburtstag) unverzüglich und unabhängig vom späteren initialen THT- und/oder IFN- $\gamma$-Testresultat mit der täglichen Gabe von Isoniazid (INH) zu beginnen (Chemoprophylaxe) [92][93], sofern die Diagnose beim Indexpatienten gestellt und eine Tuberkulose der Thoraxorgane beim Kind radiologisch ausgeschlossen ist. Die Kinder sind unverzüglich, entsprechend den Ausführungen in 3.5.3, mittels eines THT zu untersuchen ([Abb. 2]). Hierbei ist eine enge Zusammenarbeit mit dem betreuenden Pädiater, auch zwecks Verordnung des INH und Durchführung der Behandlung sowie klinischer, radiologischer und laborchemischer Verlaufskontrollen, angezeigt.

Bei initial positivem THT ist ein IFN- $y$-Test als Bestätigung durchzuführen, um die Möglichkeit falschpositiver Resultate durch eine frühere Infektion mit NTM oder nicht mehr eruierbare BCG-Impfung zu minimieren. Ist letzterer Test diskordant negativ, sollte er acht[7] Wochen nach der letzten Exposition (= Latenzzeit) wiederholt werden; bleibt er negativ, wird die Prophylaxe beendet.

Wenn der IFN- $\mathrm{Y}$-Test im Anschluss an einen initial positiven THT z. B. wegen schlechter Venenverhältnisse nicht durchgeführt werden kann, ist das Kind chemopräventiv über neun Monate zu behandeln; sicherheitshalber sollte nach drei Monaten eine weitere TRU erfolgen. 
Negative THT (Indurationsdurchmesser $\leq 5 \mathrm{~mm}$ ) oder negative IFN- $\gamma$-Tests sollten sicherheitshalber acht[7] Wochen nach dem letzten Kontakt zum Indexfall wiederholt werden. Wenn das Ergebnis des anfänglich negativen THT oder des IFN- $\gamma$-Tests nunmehr positiv ausfällt, ist dies bei nachgewiesener Exposition als Konversion aufgrund einer frischen Infektion mit $M$. tuberculosis zu bewerten. Ein falsch-positives Testresultat ist im Fall dieser THT-Konversion unwahrscheinlich und eine Bestätigung durch einen IFN- $\gamma$-Test somit entbehrlich. Nach Ausschluss einer Tuberkulose der Atmungsorgane mittels erneuter klinischer Untersuchung und nochmaliger Durchführung einer TRU sollte die Chemoprophylaxe als Chemoprävention (in aller Regel mit INH über insgesamt neun Monate, s. 3.8.2.5) weitergeführt werden.

Ist das Ergebnis des THT oder des IFN-ץ-Tests jedoch erneut negativ, wird dies als Ausschluss einer LTBI gewertet. Es wird empfohlen, dann von weiteren Untersuchungen abzusehen und die eingeleitete chemoprophylaktische Behandlung nach acht[7] Wochen abzusetzen.

Bei radiologischem Verdacht auf das Vorliegen einer Tuberkulose der Atmungsorgane bzw. Hinweisen auf das Vorliegen einer extrapulmonalen Tuberkulose erfolgt unmittelbar die weiterführende Diagnostik. Nur wenn sich der anfängliche Tuberkuloseverdacht nicht bestätigt, ist je nach THT- bzw. IFN- $\mathrm{y}$-Test-Ergebnis der oben genannten Vorgehensweise zu folgen ([Abb. 2]).

\subsubsection{Kontaktpersonen von 5 bis unter 15 Jahren}

Kontaktpersonen im Alter von 5 - 14 Jahren, auf die keine der in Absatz 3.8.2.1 genannten Indikationen für eine TRU zutrifft, sind klinisch zu untersuchen. Auch sollte unverzüglich bei Kindern ohne BCG-Impfung ein THT oder ein IFN-Y-Test durchgeführt werden ([Abb. 3]). Gegenüber dem Vorgehen bei Kindern unter 5 Jahren entfallen die sofortige TRU sowie die Einleitung einer Chemoprophylaxe (s. 3.8.2.2).

Bei initial positivem THT ist ein IFN- $\gamma$-Test als Bestätigung durchzuführen, um falsch-positive Ergebnisse weitgehend auszuschließen. Falls letzterer Test diskordant negativ ausfällt, sollte er acht[7] Wochen nach der letzten Exposition wiederholt werden. Bleibt er negativ, erfolgen keine weiteren Maßnahmen.

Kinder sind nach radiologischem Ausschluss einer Tuberkulose der Thoraxorgane chemopräventiv über neun Monate zu behandeln, wenn

- der IFN- - -Test initial positiv reagiert oder

- der IFN-Y-Test im Anschluss an einen initial positiven THT nicht durchführbar ist oder

- ein initial negativer Test nach acht[7] Wochen in eine positive Reaktion umschlägt (THT- oder IFN- $\gamma$-Test-Konversion).

Bietet aber bereits die klinische Untersuchung und/oder die TRU Anhaltspunkte für eine manifeste Erkrankung, sind weitere diagnostische Schritte zu veranlassen. Falls im Rahmen dieser Untersuchungen eine Tuberkulose ausgeschlossen wird, kann nach den oben genannten Ausführungen vorgegangen werden.

Bleibt ein initial negativer THT bzw. IFN- $y$-Test acht[7] Wochen nach der letzten Exposition negativ, erfolgen keine weiteren Maßnahmen ([Abb. 3]).

Für Kinder dieser Altersgruppe kommt, insbesondere wenn Faktoren für ein erhöhtes Infektions- bzw. Erkrankungsrisiko vorliegen, grundsätzlich auch eine Chemoprophylaxe und ein Vorgehen nach 3.8.2.2 in Betracht ([Abb. 2]).

\subsubsection{Kontaktpersonen ab 15 Jahren}

Bei Personen ab einem Alter von 15 Jahren, auf die keine der in Absatz 3.8.2.1 genannten Eigenschaften zutrifft, sollte nach Bekanntwerden der Tuberkulose des Indexpatienten ein IFN- $y$-Test vorzugsweise acht Wochen nach der letzten Infektionsmöglichkeit, d. h. nach Ablauf der 
präallergischen Phase, angelegt werden, da ansonsten bei negativem Ergebnis ein Wiederholungstest erforderlich wird. Bei negativem Ausfall kann von weiteren Maßnahmen abgesehen werden. Sofern die unter Punkt 3.8.2.1 genannten Voraussetzungen vorliegen, ist die Indikation zur umgehenden TRU großzügig zu stellen. Ergeben sich bei der klinischen Untersuchung und/oder der TRU Hinweise auf eine Tuberkulose, ist eine weitere Diagnostik erforderlich, selbst wenn der IFN- $\mathrm{y}$-Test negativ ausgefallen ist.

Bei positivem IFN- $y$-Test wird, sofern keine Kontraindikationen vorliegen, eine Chemoprävention und eine TRU nach Behandlungsabschluss empfohlen, um eine sich eventuell trotz Chemoprävention entwickelnde Tuberkulose (z. B. bei unbekannter INH-Resistenz) auszuschließen.

Bei Kontaktpersonen, die 50 Jahre oder älter sind, müssen aufgrund des mit dem Lebensalter ansteigenden Risikos einer INH-Hepatitis oder anderer unerwünschter Arzneimittelwirkungen die Risiken einer Behandlung gegenüber dem Nutzen sorgfältig abgewogen werden. Im Falle einer präventiven Therapie der LTBI sollten daher engmaschige Kontrollen erfolgen [94]. Ist unter Berücksichtigung des individuellen Risikoprofils bzw. bei fehlender Compliance keine präventive Chemotherapie vorgesehen, kann bei diesen Kontaktpersonen statt eines IFN- $\gamma$-Tests alternativ umgehend eine TRU durchgeführt werden. Eine weitere TRU kommt dann im Laufe des ersten Jahres, z. B. neun Monate nach der initialen TRU, in Betracht (s. 3.8.2.6) ([Abb. 4]).

\subsubsection{Chemoprophylaxe und Chemoprävention}

Im Unterschied zur Chemoprävention, bei der nachweislich infizierte Personen behandelt werden, soll bei exponierten Kontaktpersonen die Entwicklung einer LTBI durch die Chemoprophylaxe verhindert werden, noch bevor THT- bzw. IFN- $y-T e s t$ positiv ausfallen. In erster Linie ist die Chemoprophylaxe bei Kindern unter 5 Jahren indiziert (s. 3.8.2.2). Bei älteren Kindern ( $\geq 5$ Jahren) und Erwachsenen besteht selten eine Indikation zur Chemoprophylaxe. Sie kann aber altersunabhängig bei exponierten Kontaktpersonen, die eine angeborene, erworbene (HIV) oder medikamentös induzierte Immunschwäche haben, indiziert sein, um eine Infektion bzw. das Fortschreiten einer ganz frischen und daher noch nicht nachweisbaren tuberkulösen Infektion zu einer aktiven Tuberkulose zu verhindern.

Die Chemoprophylaxe erfolgt nach radiologischem Ausschluss einer Tuberkulose der Thoraxorgane und fehlendem Hinweis auf eine INH-Resistenz des Indexfalls unverzüglich mit der täglichen Gabe von INH (200 mg/m² Körperoberfläche bis 15 Jahre, Höchstdosis $300 \mathrm{mg} /$ die), alternativ können die Dosen per Kilogramm Körpergewicht kalkuliert werden [93]; beim Erwachsenen 300 mg/die). Bezüglich der korrekten Durchführung und möglicher alternativer Therapieregime, z. B. mit RMP über 4 Monate bei vermuteter INH-Resistenz, wird auf die geltenden Empfehlungen des DZK verwiesen [95]. In Abhängigkeit vom Ergebnis des THT bzW. IFN- $\gamma$-Tests (s. 3.8.2.2) wird, sofern eine Infektion nicht stattgefunden hat bzw. verhindert werden konnte, die Chemoprophylaxe nach acht[7] Wochen beendet.

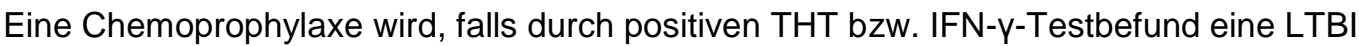
nachgewiesen wird, als Chemoprävention fortgesetzt (in aller Regel INH über eine Gesamtdauer von neun Monaten). Bei fehlender Akzeptanz einer chemoprophylaktischen bzw. chemopräventiven Behandlung sollten die betroffenen Personen bzw. Sorgeberechtigten ausdrücklich über die potenziellen Symptome einer Tuberkulose informiert und dieses sorgfältig dokumentiert werden (s. auch 3.6).

Bei regelmäßiger Medikamenteneinnahme ist lediglich eine weitere TRU nach Therapieabschluss erforderlich, um eine sich eventuell trotz Chemoprävention entwickelnde Tuberkulose (z. B. bei unbekannter INH-Resistenz) auszuschließen. Bei Kindern unter 5 Jahren, die eine Chemoprävention einnehmen, wird eine TRU bereits nach 3 Monaten empfohlen, eine weitere TRU nach Therapieabschluss kann fakultativ durchgeführt werden (siehe [Abb. 2]). 


\subsubsection{Radiologische Verlaufsbeobachtung}

Nachuntersuchungen mit der TRU dienen dem Ziel, Tuberkulosen der Thoraxorgane in einem frühen Stadium festzustellen. Dabei ist zu berücksichtigen, dass die Wahrscheinlichkeit einer Tuberkulose innerhalb des ersten Jahres nach einer Infektion mit MTB höher als im zweiten Jahr und deutlich höher als in den folgenden Jahren ist. So entwickelten im ungeimpften Studienarm einer BCGImpfstudie 121 von 2550 britischen Kindern (4,7\%) innerhalb von 15 Jahren nach Exposition eine Tuberkulose; hiervon entfielen $54 \%$ auf das erste Jahr, insgesamt $82 \%$ entwickelten sich binnen zweier Jahre [25].

Unter Kosten- und Strahlenschutzgesichtspunkten kann die radiologische Verlaufsbeobachtung jedoch weder ausreichend engmaschig noch über einen ausreichenden Zeitraum durchgeführt werden. Daher ist es vertretbar, bei Kontaktpersonen, bei denen eine LTBI anzunehmen ist und die keine Chemoprävention mit INH durchgeführt haben, nach der initialen TRU im Laufe des ersten Jahres lediglich eine weitere Thorax-Röntgenaufnahme, z. B. nach neun Monaten analog der Kontrollaufnahme nach Abschluss einer Chemoprävention [94], durchzuführen. Dies setzt aber voraus, Kontaktpersonen obligat über das mit einer LTBI verbundene Erkrankungsrisiko und mögliche Tuberkulosesymptome selbst nach Jahren mit dem Ziel einer sensiblen Wahrnehmung erster eigener Symptome aufzuklären (s. 3.6) und dass eine Untersuchung für sog. Selbstmelder mit Tuberkuloseverdacht durchgeführt wird. In speziellen Risikogruppen, z. B. bei Bewohnern von Obdachlosenheimen oder Suchtkranken, wird man wegen ungenügender Compliance häufig nicht davon ausgehen können, dass beim Auftreten von Symptomen tatsächlich ein Arzt aufgesucht wird. Deshalb sollten bei Ausbruchssituationen in solchen Einrichtungen infizierte Kontaktpersonen, die keine präventive Therapie erhielten, über einen längeren Zeitraum und/oder in kürzeren Intervallen wiederholt geröntgt werden, um Folgeerkrankungen möglichst frühzeitig zu erkennen.

\subsubsection{Nachtesten von engen Kontaktpersonen mit dem Interferon- $\gamma-T e s t$}

Bereits vor der Einführung des IFN-y-Tests war das Phänomen der Konversion gut dokumentiert am Beispiel eines zuvor negativen THT (in den positiven Bereich oberhalb des jeweils gewählten Grenzwertes) bzw. umgekehrt die Reversion eines zuvor positiven THT (in den als test-negativ bewerteten Bereich) bei wiederholtem Testen desselben Probanden in unterschiedlichen Kollektiven, wie z. B. beim seriellen Testen von Beschäftigten im Gesundheitswesen [96]. Neben einer im Einzelfall möglichen Elimination der mykobakteriellen Last oder einer auch nur vorübergehenden individuellen Verminderung der T-Zell-Reaktivität gegenüber mykobakteriellen Antigenen [97] kommt hier als Erklärung vor allem eine allgemeine testtheoretische Problematik bei Screeningtests mit suboptimaler Sensitivität und Spezifität, ungeachtet der Art der untersuchten Infektion bzw.

Erkrankung, in Betracht [98].

In Abhängigkeit vom PPW und NPW des gewählten Tests und konstanter Sensitivität (Se) und Spezifität (Sp) ist bei seriellem Testen allgemein eine Konversionsrate von (1-NPW) (Se) + NPW(1$\mathrm{Sp})$ sowie eine Reversionsrate von PPW (1-Se)+(1-PPW)(Sp) zu erwarten [99]. Ist die Spezifität eines Tests hoch, steigt die zufallsbedingte Reversionsrate nach positivem Testergebnis mit abnehmender Infektionsprävalenz im untersuchten Kollektiv (s. [Tab. 5]). Erwartungsgemäß werden daher wie beim THT auch beim Nachtesten von Kontaktpersonen mit positiven IFN- $\gamma$-Ergebnissen (sofort bis Monate nach dem ersten Test) immer wieder Reversionen beobachtet [100][101][102].

Aufgrund des fehlenden Goldstandards für die Detektion einer LTBI ist bei einem zweiten, jetzt negativen Testergebnis eine Unterscheidung zwischen einem zuvor falsch positiven IFN-y-Ergebnis des initialen Tests, einer zwischenzeitlichen Elimination von M. tuberculosis und einer zufallsbedingten Reversion nicht möglich. In den wenigen bislang vorliegenden Progressionsstudien entwickelten wenngleich in geringerem Maße - auch Kontaktpersonen mit initial niedrigen Testwerten innerhalb der ersten Jahre eine aktive Tuberkulose [81][82][100], sofern ein enger Kontakt dokumentiert war. Bei einem definierten aktuellen Kontakt zu einem infektiösen Indexfall und entsprechend hoher Prävalenz einer Infektion, die im Gegensatz hierzu beim routinemäßigen Screening von Beschäftigten im Gesundheitswesen nicht bekannt ist, sollte bei jeder IFN-y-testpositiven Kontaktperson daher - wie früher beim THT auch - nach Ausschluss einer Organtuberkulose von einer LTBI ausgegangen und demnach eine Chemoprävention empfohlen werden. 
Insbesondere eine Einteilung der IFN- $\gamma$-Testergebnisse in „Schwach”- oder „Stark”-Positive und eine eventuelle Nachtestung nur der „Schwach”-Positiven zu einem willkürlich gewählten Zeitpunkt sind weder aussagekräftig noch sinnvoll, da ein signifikanter Zusammenhang zwischen einer bestimmten Höhe des IFN- $\gamma$-Testergebnisses und der nachfolgenden Reversion bei Kontaktpersonen bislang nicht nachgewiesen wurde.

\section{Sonderfälle}

\subsection{Umgebungsuntersuchungen in Schulen, Kindergärten und anderen Gemeinschaftseinrichtungen für Kinder und Jugendliche}

Bei Tuberkulose in Schulen, Kindergärten etc. (§ 33 IfSG) hat es sich bewährt, unverzüglich nach Eingang der Meldung mit der Leitung der Einrichtung Kontakt aufzunehmen, um die erforderlichen Maßnahmen zu besprechen und die Vorgehensweise zu vereinbaren. Die Eltern der betroffenen Kinder sollten hierüber vorab informiert sein.

Die Sorgeberechtigten sind in geeigneter Form (Merkblatt, Gespräch, Elternabend, Telefon-Hotline) zu informieren und über typische Symptome der Krankheit aufzuklären[8]. Es wird empfohlen, mit Hilfe eines Fragebogens Informationen zum Kontakt und zur Anamnese zu erheben und gleichzeitig das Einverständnis der Sorgeberechtigten für die ggf. notwendigen Untersuchungen trotz Duldungspflicht (§ 26 Abs. 2 IfSG) einzuholen [103].

Die Ermittlungen sollten sich bei einem Schüler mit ansteckungsfähiger Lungentuberkulose nicht nur auf die Klassenkameraden, sondern auch auf die Schüler erstrecken, mit denen in Arbeitsgemeinschaften, auf Klassenfahrten, im Schulorchester, Chor etc., Kontakt bestand.

Geht von einer Lehrkraft, einem zur Vorbereitung auf den Beruf des Lehrers in der Schule Tätigen, einem Schulbediensteten oder einem Bewohner eines Schulgebäudes die Ansteckungsgefahr aus, sollten alle, die von dieser Person unterrichtet wurden und mit ihr engen Kontakt hatten, sowie alle Kollegen untersucht werden.

Sollte der Schulbusfahrer als Indexfall gelten, wird empfohlen, alle Schüler, die regelmäßig diesen Bus benutzen, in die Umgebungsuntersuchung mit einzubeziehen.

Die Untersuchungen sollten unverzüglich gemäß 3.8.1 erfolgen, um Infizierte (LTBI) zu entdecken und durch die Empfehlung einer Chemoprävention und deren Durchführung durch niedergelassene Ärzte Folgeerkrankungen zu verhindern [104].

Handelt es sich um den Kranken oder Krankheitsverdächtigen, wird der Schulbesuch solange untersagt, bis die Untersuchungsergebnisse eine Weiterverbreitung der Erreger nicht mehr befürchten lassen (§ 34 Abs. $1 \mathrm{Nr}$. 8 IfSG). Dies ist nach den Hinweisen des RKI bei einer lege artis durchgeführten antituberkulösen Kombinationstherapie in der Regel nach drei Wochen der Fall, wenn aufeinanderfolgend drei mikroskopisch negative Proben von Sputum (ggf. Bronchialsekret oder Magensaft) vorliegen [105][106].

\subsection{Umgebungsuntersuchungen in Betrieben}

In vielen Fällen reichen die Angaben der Indexperson über Kontaktpersonen am Arbeitsplatz aus. Wenn diese Angaben verweigert werden, unzutreffend oder ergänzungsbedürftig erscheinen, wird empfohlen, die Betriebsleitung und den Betriebsarzt über die notwendigen Maßnahmen zu informieren, da genaue Kenntnisse der Betriebsorganisation erforderlich sind, um Möglichkeiten und Intensität des Kontaktes, wie in 3.8.1 beschrieben, abzuschätzen und um den Umfang der Umgebungsuntersuchungen festzulegen.

Es empfiehlt sich, wenn mehr als zehn Personen betroffen sind, IFN- $y$-Tests möglichst im Betrieb durchzuführen, und für Testpositive eine Freistellung für eine umgehende TRU zu erwirken, um 
weitere unerkannte Tuberkulosefälle rasch und kostengünstig auszuschließen.

\subsection{Umgebungsuntersuchungen bei im Gesundheitswesen Beschäftigten}

Ziel und Inhalt der arbeitsmedizinischen Vorsorgeuntersuchungen bei Beschäftigten im Gesundheitswesen haben sich in den beiden letzten Dekaden deutlich verändert. Bis 1982 waren ein positiver THT Voraussetzung für die Beschäftigung im Gesundheitsdienst und bis 1998 regelmäßige arbeitsmedizinische Vorsorgeuntersuchungen verpflichtend für alle Beschäftigten im Gesundheitswesen. Mit der sich verändernden, günstigen Inzidenzlage in Deutschland wurde der Kreis der zu untersuchenden Beschäftigten in der Biostoffverordnung vom 27. 1. 1999 [107] neu definiert und ein Paradigmenwechsel hin zu anlassbezogenen Angebotsuntersuchungen nach dem Verdacht auf eine berufliche Exposition gegenüber bestimmten Infektionserregern - hier $M$. tuberculosis - vorgenommen.

Seit dem 1. 1. 2010 wird die Biostoffverordnung durch die Verordnung zur Arbeitsmedizinischen Vorsorgeuntersuchung (ArbMedVV) vom 18. Dezember 2008, BGBI. I S. 2768 ergänzt; inhaltlich hat sich jedoch keine Veränderung ergeben: „Wenn als Folge einer Exposition gegenüber biologischen Arbeitsstoffen mit einer schweren Infektion oder Erkrankung gerechnet werden muss und Maßnahmen der postexpositionellen Prophylaxe möglich sind" ( 55 Abs. 2 i. V. m. Teil 2,2

Angebotsuntersuchungen 2 ArbMedVV), sind den Beschäftigten zu Lasten des Arbeitgebers unverzüglich Untersuchungen nach § 15 Abs. 2 Nr. 4 (Untersuchungen aus besonderem Anlass) anzubieten. Regelmäßige Pflichtuntersuchungen sind gemäß Teil 2,1 der ArbMedVV nur noch bei Beschäftigten in Tuberkuloseabteilungen und anderen pulmologischen Einrichtungen oder Forschungseinrichtungen/Laboratorien, die regelmäßig Kontakt zu infektiösen Patienten oder Materialien haben, vorgesehen.

Die freiwillige Teilnahme an einer Angebotsuntersuchung bei Kontakt eines Beschäftigten mit einem Tuberkulose-Indexfall ersetzt dabei, wie die arbeitsmedizinische Pflichtuntersuchung unter Beachtung des Grundsatzes G 42 Nr. 37 (Tuberkulose) auch, die Umgebungsuntersuchung nach dem IfSG. Um Doppeluntersuchungen zu vermeiden, ist es sinnvoll, dass Betriebsärzte ihre Untersuchungen nach der Biostoffverordnung in Absprache mit dem Gesundheitsamt vornehmen und sowohl die Kriterien für enge Kontaktpersonen (3.8.1) als auch das entsprechende Untersuchungsschema dieser DZKEmpfehlungen anwenden. Bei Beschäftigten, die die Angebotsuntersuchungen nicht wahrnehmen, bleiben die Verpflichtung und die Berechtigung des Gesundheitsamtes zur Umgebungsuntersuchung nach dem IfSG unberührt.

Frische LTBI sind zudem entsprechend der Berufskrankheitenverordnung bei Verdacht auf berufliche Verursachung wie eine manifeste Tuberkulose dem Unfallversicherungsträger oder der für den medizinischen Arbeitsschutz zuständigen Berufsgenossenschaft anzuzeigen [108]. Die Anzeige erfolgt durch den feststellenden Arzt. Zwar begründet auch die Konversion im THT eine Verdachtsanzeige auf das Vorliegen einer Berufskrankheit. Aufgrund der dem THT überlegenen Spezifität des IFN-y-Tests (keine Kreuzreaktion bei BCG-Impfung und durch NTM-Infektionen, s. 3.5.2) ist der THT für die Diagnose einer LTBI jedoch nur begrenzt geeignet und bedarf im nachfolgenden Berufskrankheiten-Verfahren der Bestätigung durch einen IFN- $\mathrm{y}-\mathrm{Test}$. In einer multizentrischen Querschnittsstudie bei exponierten Beschäftigten im Gesundheitswesen wurde lediglich die Hälfte der positiven THT-Resultate durch den IFN-ץ-Test bestätigt [109].

Anders als bei Umgebungsuntersuchungen in der Allgemeinbevölkerung ist es für Beschäftigte im Gesundheitswesen nicht unwahrscheinlich, dass sie mehrmals im Laufe ihrer Tätigkeit auf eine LTBI hin untersucht werden. Der Booster-Effekt des THT ist für sie daher von besonderer Bedeutung. Da dieser Booster-Effekt nicht nur kurzfristig über wenige Wochen, sondern länger anhält [110], kann der THT bei Beschäftigten im Gesundheitswesen nicht mehr empfohlen werden. Sowohl bei Untersuchungen vor Aufnahme der Beschäftigung im Gesundheitswesen, sofern indiziert, als auch bei der Umgebungsuntersuchung mit dem Ziel einer LTBI-Detektion und postexponentiellen Chemoprävention ist der IFN- $\gamma$-Test dem THT auch deshalb überlegen. Eine primäre betriebsärztliche Anwendung des IFN- $y$-Tests ist daher - auch um den organisatorischen Aufwand und die Belastung des Beschäftigten möglichst gering zu halten und einen eventuellen Booster-Effekt durch den THT zu vermeiden - geboten. 
Ein IFN-y-Test ist bei Beschäftigten im Gesundheitswesen auch durchzuführen, wenn keine Chemoprävention geplant ist. Nur so kann eine LTBI, die als Berufskrankheit zu melden ist, diagnostiziert werden. Der alleinige Ausschluss einer aktiven Tuberkulose mittels TRU ist bei Beschäftigten im Gesundheitswesen also nicht ausreichend.

Im Übrigen gelten die Empfehlungen wie unter 3.8.1 ausgeführt.

Im Falle einer Umgebungsuntersuchung nach dem IfSG informiert das Gesundheitsamt den jeweiligen Leiter der Einrichtung - in Krankenhäusern die ärztliche Leitung - von der Notwendigkeit der Umgebungsuntersuchung. Abgesehen vom Personal müssen enge Kontaktpersonen unter den Mitpatienten ermittelt werden; auch an Beschäftigte privater Reinigungsfirmen oder an technisches Personal sollte gedacht werden. Eine Liste ist anzufertigen, aus der Namen, Geburtsdatum und Anschrift hervorgehen. In ihr können die Ergebnisse der Untersuchungen vermerkt werden, soweit diese im Krankenhaus stattgefunden haben. Die Liste erhält zuständigkeitshalber das Gesundheitsamt als Grundlage zur Planung der Umgebungsuntersuchung.

\subsection{Umgebungsuntersuchungen in Alten- und Pflegeheimen sowie Betreuungseinrichtungen}

Während Tuberkulin-Hauttests bei älteren Menschen wegen bekannter Störfaktoren unzuverlässig sind, steht bei Umgebungsuntersuchungen in Pflege- und Betreuungseinrichtungen mit dem IFN-YTest eine Alternative zur sofortigen Röntgenaufnahme zur Verfügung. Testpositive Bewohner, die vor einem Röntgenstativ stehen können, erhalten anschließend eine TRU. Gehaltene Aufnahmen, bei denen sich Helfer während der Aufnahme im Kontrollbereich aufhalten, sind nicht zu empfehlen.

Es wird empfohlen, bei Bettlägerigen statt der TRU drei Sputumproben, ggf. auch die Untersuchung von Magensaft, zu veranlassen [111], auch wenn man damit in Kauf nimmt, die Tuberkulose erst im fortgeschrittenen Stadium entdecken zu können. Sofern dies nicht möglich ist, sollte eine klinische Überwachung durch den behandelnden Arzt erfolgen. Bei symptomatischen Bewohnern ist im Einzelfall eine TRU im Liegen zu veranlassen.

Insbesondere in Heimen für behinderte Menschen kann es unter Umständen nahezu unmöglich sein, die verschiedenen Kontakte der zurückliegenden Monate in Wohngemeinschaften, Wohnheimen, Schule und Werkstätten zu ermitteln, sodass sich der zu untersuchende Personenkreis kaum sicher eingrenzen lässt [112]. Entsprechend großzügig ist die Indikation zur Untersuchung zu stellen. Die Umgebungsuntersuchungen richten sich für Bewohner und Personal nach den o. g. Ausführungen. Es hat sich bewährt, die behandelnden Ärzte der Heimbewohner über den Tuberkulose-Kontakt ihrer Patienten zu unterrichten, um zu einer optimierten Fallfindung beizutragen.

\subsection{Umgebungsuntersuchungen in Justizvollzugsanstalten}

Umgebungsuntersuchungen in Gefängnissen und ähnlichen Einrichtungen sind im Einvernehmen mit dem ärztlichen Dienst der jeweiligen JVA nach dem dargestellten Schema durchzuführen und auf die Beschäftigten der JVA auszudehnen. Bei der Durchführung von Röntgen-Thoraxaufnahmen sollte vermieden werden, die gleichen Kontaktpersonen in recht kurzen Abständen wiederholt zu röntgen.

Konsequente ärztliche Untersuchungen einschließlich der duldungspflichtigen TRU ( $\$ 36$ Abs. 4 IfSG) bei Aufnahme eines Häftlings in die JVA tragen dazu bei, Tuberkulosefälle frühzeitig zu erkennen sowie mögliche Übertragungen vom M. tuberculosis und damit Umgebungsuntersuchungen innerhalb der JVA zu vermeiden [113].

\subsection{Umgebungsuntersuchungen bei Flugreisenden oder Nutzern anderer Verkehrsmittel}

Grundsätzlich wird nach dem o. g. Schema verfahren, wobei nach den internationalen Richtlinien der Weltgesundheitsorganisation (WHO) ein Infektionsrisiko in der Regel lediglich für Mitpassagiere desselben Kabinenabschnitts (wenige Reihen vor und hinter dem Indexfall) nach einer Flugdauer von mehr als acht Stunden angenommen wird [114][115]. 
Bei Langstreckenreisen mit anderen Verkehrsmitteln, wie Bus oder Bahn, ist, sofern Kontaktpersonen im Bus bzw. gleichen Zugabteil ausgemacht werden können (z. B. Klassenfahrt), gemäß den vorherigen Ausführungen zu verfahren.

\subsection{Ausbrüche}

Umgebungsuntersuchungen mit mehreren Folgefällen können unter Umständen Screeninguntersuchungen (IFN-Y-Tests, THT, Röntgenbus) von größeren Gruppen der Bevölkerung notwendig machen, deren Bewältigung die personellen Kapazitäten des örtlich zuständigen Gesundheitsamtes übersteigt. In drohenden Ausnahmesituationen sind frühzeitig die übergeordneten Stellen des Öffentlichen Gesundheitsdienstes zu informieren, damit unter Umständen zusätzliches Fachpersonal zur Unterstützung abgeordnet werden kann.

\section{Organisation}

\subsection{Aufforderungsschreiben und weitere Maßnahmen}

Nach Abschluss der Ermittlungen werden die Kontaktpersonen zu den notwendigen Untersuchungen im Gesundheitsamt aufgefordert. Das kann heutzutage auch umgehend telefonisch erfolgen, z. B. wenn Kinder in der Familie eines Patienten mit ansteckungsfähiger Tuberkulose als Kontaktpersonen ermittelt wurden oder es bei einem an Tuberkulose erkrankten Kind um eine Quellensuche geht.

Das erste Schreiben sollte über die Notwendigkeit der Untersuchung Auskunft geben.

Zweckmäßigerweise wird ein Merkblatt mit allgemeinen Informationen zur Tuberkulose[9] beigelegt. Es ist darauf hinzuweisen, dass dieser Aufforderung gemäß gesetzlicher Grundlagen Folge zu leisten ist und die notwendigen Untersuchungen duldungspflichtig sind.

Erfolgt auf die erste Aufforderung innerhalb von zwei Wochen keine Reaktion, wird ein zweites Schreiben versandt, in dem ein deutlicher Hinweis auf die Bestimmungen des IfSG (§§ 26 in Verbindung mit § 16) und auf eine mögliche Geldbuße gegeben wird.

Wird auf beide Schreiben nicht reagiert, ist zu prüfen, ob weitere Maßnahmen erforderlich sind, um der Aufforderung Nachdruck zu verleihen. Je höher das Infektions- und Erkrankungsrisiko nach den in 2.4 bis 2.6 genannten Faktoren einzuschätzen ist, desto größere Anstrengungen sind notwendig, um eine Tuberkulose bei einer Kontaktperson auszuschließen. Dies gilt insbesondere für Kinder aus dem Haushalt eines Indexfalles und für Personen mit einer hohen Frequenz sozialer Kontakte in Innenräumen, wie z. B. Lehrer, Erzieher, Friseure, Gastwirte.

Als erste Maßnahme ist dann ein Hausbesuch, ggf. mit Dolmetscher, durchzuführen. Führt dies nicht weiter, ist zu prüfen, ob ein Zwangsgeld angedroht oder verhängt werden kann. Darüber hinaus kann ein Bußgeld nach § 73 IfSG durch die zuständige Behörde verhängt werden. Weiterhin können Kranke und Krankheitsverdächtige nach § 28 IfSG individuell angepasste Auflagen erhalten und nach $\S 29$ IfSG einer Beobachtung unterworfen werden. Nach § 31 IfSG kann innen die Ausübung bestimmter beruflicher Tätigkeiten ganz oder teilweise untersagt, nach § 34 IfSG das Betreten der Räume, das Benutzen der Einrichtung und die Teilnahme an Veranstaltungen der Gemeinschaftseinrichtung verboten werden.

Zur zwangsweisen Durchsetzung von Umgebungsuntersuchungen (Anforderung polizeilicher Vollzugshilfe durch das Gesundheitsamt nach § 26 Abs. 2 IfSG) oder von Quarantänemaßnahmen (nur nach richterlichem Beschluss gemäß $\S 30$ IfSG) bestehen unterschiedliche Rechtsauslegungen [40][41]. Das hierfür in Frage kommende Vorgehen sollte daher sehr sorgfältig gemeinsam mit den Juristen der zuständigen Ordnungsbehörde abgewogen werden. 


\subsection{Kosten}

Die Kosten für die Durchführung der Ermittlungen und Untersuchungen der Kontaktpersonen (inkl. IFN- $y$-Tests) sind aus öffentlichen Mitteln zu bestreiten (§ 69 IfSG); die Finanzierung wird daher vom Gesundheitsamt übernommen. Bei Delegation von Teilen der Untersuchungen durch das Gesundheitsamt, z. B. an niedergelassene Kinderärzte, hat das Gesundheitsamt die Kosten zu erstatten. Die seit dem 1. Januar 2011 geltende Gebührenordnungsposition der Gesetzlichen Krankenversicherung (EBM-Abrechnungsziffer 32670) schließt in ihren Indikationen die Kostenübernahme für IFN- $\gamma$-Tests bei Umgebungsuntersuchungen ausdrücklich aus. Werden betriebsärztlicherseits Umgebungsuntersuchungen als sog. Angebotsuntersuchungen gemäß der ArbMedVV (s. 4.3) veranlasst, so trägt der jeweilige Arbeitgeber die Kosten. Sucht der Betroffene einen Arzt seiner Wahl auf, können die dabei entstandenen Kosten nicht übernommen werden.

\subsection{Kontrolle anderenorts durchgeführter Untersuchungen}

Wird die Umgebungsuntersuchung anderenorts durchgeführt, bleibt grundsätzlich das Gesundheitsamt verantwortlich. Es legt die Art der Erstuntersuchungen und die zeitlichen Abstände der Folgeuntersuchungen fest.

Werden Umgebungsuntersuchungen durch eine andere medizinische Einrichtung als durch das Gesundheitsamt durchgeführt, muss es sich von der zeitgerechten Untersuchung im methodisch gebotenen Ausmaß und von der Vollständigkeit der Befunde überzeugen. Dazu fordert das Gesundheitsamt die Befunde an. Gemäß $\S 26$ in Verbindung mit $\S 16$ IfSG sind Personen (Ärzte etc.), durch die Befunde erhoben wurden, verpflichtet, Auskunft zu erteilen und Unterlagen vorzulegen.

\subsection{Qualitätssicherung durch molekulare Stammtypisierungsmethoden}

Fragen zur endogenen Reaktivierung oder Super- bzw. Reinfektion, zur geografischen Herkunft der Erreger oder auch Zusammenhangsfragen bei Kleinepidemien können rückblickend durch molekulare Untersuchungsmethoden beantwortet werden und Aufschluss über Aus- und Weiterverbreitung der Tuberkulose in lokalen Risikogruppen geben [5][116][118][119]. Voraussetzung ist allerdings die erfolgreiche Isolierung von Tuberkulosebakterien im Untersuchungsmaterial.

Zur Aufdeckung epidemiologischer Zusammenhänge kann das Gesundheitsamt in besonderen Fällen die Übergabe von Untersuchungsmaterial z. B. zum Zwecke des DNA-Fingerprinting der Tuberkulosebakterien (z. B. RFLP-Methode oder Spoligotyping) anordnen und die Untersuchung veranlassen (§ 16 Abs. 3 IfSG). Mykobakterielle Kulturen der Labors sind gemäß DIN-Vorschrift ein Jahr aufzubewahren [111].

Da es trotz molekularbiologischer Identifizierung der epidemiologischen Klärung bedarf, ob z. B. ein Tuberkulose-Stamm von A nach B oder von B nach A weiterverbreitet wurde, hat sich an der Notwendigkeit konventioneller Umgebungsuntersuchungen nichts geändert. Allerdings eröffnet diese Untersuchungsmethodik die Möglichkeit, retrospektiv die Vorgehensweise des Gesundheitsamts bei der Auswahl der richtigen Kontaktpersonen durch Abgleich mit den im Rahmen des DNA-

Fingerprinting festgestellten Zusammenhängen zwischen Indexfall und ggf. später erkrankten Kontaktpersonen zu überprüfen. Es ist daher wünschenswert, das DNA-Fingerprinting vermehrt zur Qualitätssicherung der Umgebungsuntersuchungen einzusetzen [118][119]. 


\section{Interessenkonflikt}

R. Diel hat Reisekosten und Vortragshonorare von den Firmen Oxford Immunotec und Cellestis GmbH erhalten.

B. Königstein hat Reisekosten und Vortragshonorare von Cellestis GmbH erhalten.S. Castell, A. Detjen, H. Geerdes-Fenge, W. Haas, B. Hauer, R. Loddenkemper, G. Loytved, D. Maffei, K. Margdorf, A. Nienhaus, M. Priwitzer und J. P. Zellweger geben an, dass kein Interessenkonflikt besteht. 


\section{Literatur}

1 Deutsches Zentralkomitee zur Bekämpfung der Tuberkulose (DZK) .Empfehlungen für die Umgebungsuntersuchungen bei Tuberkulose. Gesundheitswesen 2007; 69: 488-503

2 RKI .Falldefinitionen des Robert Koch-Instituts zur Übermittlung von Erkrankungs- oder Todesfällen und Nachweisen von Krankheitserregern,. Ausgabe 2007

3 Templeton G L, Illing L A, Young L et al. The risk of transmission of Mycobacterium tuberculosis at the bedside and during autopsy. Ann Int Med 1995; 122: 922-925

4 Riley R L. The contagiosity of tuberculosis. Schweiz Med Wochenschr 1983; 113: 75-79

5 Diel R, Schneider S, Meywald-Walter K et al. Epidemiology of tuberculosis in Hamburg, Germany: long-term population-based analysis applying classical and molecular epidemiological techniques. J Clin Microbiol 2002; 40: 532-539

6 Behr M A, Warren S A, Salamon H et al. Transmission of Mycobacterium tuberculosis from patients smear-negative for acid-fast bacilli. Lancet 1999; 353: 444-449

7 Loudon R G, Spohn S K. Cough frequency and infectivity in patients with pulmonary

tuberculosis. Am Rev Resp Dis 1969; 99: 109-111

8 Loudon R G, Roberts R M. Droplet expulsion from the respiratory tract. Am Rev Respir Dis 1966; 95 : 435-442

9 Curtis A B, Ridzon R, Vogel R et al. Extensive transmission of Mycobacterium tuberculosis from a child. N Engl J Med 1999; 341: 1491-1495

10 Sultan L, Nyka W, Mills C et al. Tuberculosis disseminators: a study of the variability of aerial infectivity of tuberculosis patients. Am Rev Respir Dis 1960; 82: 358-369

11 Kenyon T A, Valway S E, Ihle W W et al. Transmission of multidrug-resistant Mycobacterium tuberculosis during a long airplane flight. N Engl J Med 1996; 334: 933-938

12 Behr M A, Hopewell P C, Paz E A et al. Predictive value of contact investigation for identifying recent transmission of Mycobacterium tuberculosis. Am J Respir Crit Care Med 1998; 158: 465-469

13 Diel R, Seidler A, Nienhaus A et al. Occupational risk of tuberculosis transmission in a low incidence area. Resp Res 2005; 6: 35

14 Veen J. Microepidemics of tuberculosis: the stone-in-the-pond principle. Tuber Lung Dis 1992; 73:

73-76

15 Khan E A, Starke J R. Diagnosis of tuberculosis in children: increased need for better

methods. Emerg Infect Dis 1995; 1: 115-123

16 Elwood R K, Cook J K, Hernández-Garduño E. Risk of tuberculosis in children from smear-negative source cases. Int J Tuberc Lung Dis 2005; 9: 49-55

17 American Thoracic Society .Targeted tuberculin testing and treatment of latent tuberculosis infection. Am J Respir Crit Care Med 2000; 161: S221-S247

18 Keane J, Gershon S, Wise R P et al. Tuberculosis associated with infliximab, a tumor necrosis $\alpha-$ neutralizing agent. N Engl J Med 2001; 354: 1098-1104

19 Morgenroth K, Schnabel R. Pathogenese und Pathomorphologie der Tuberkulose.. In:

Konietzko N, Loddenkemper R, Hrsg. Tuberkulose.. Stuttgart: Thieme; 1999

20 Wallgren A. Time-table of tuberculosis. Tubercle 1948; 29: 250-253

21 Comstock G, Edwards P. The competing risks for tuberculosis and hepatitis for adult tuberculin reactors. Am Rev Respir Dis 1975; 111: 5763-577

22 Tufariello J M, Chan J, Flynn J L. Latent tuberculosis: mechanisms of host and bacillus that contribute to persistent infection. Lancet Infec Dis 2003; 3: 578-590

23 Marks G B, Bai J, Simpson S E et al. Incidence of tuberculosis among a cohort of tuberculinpositive refugees in Australia: reappraising the estimates of risk. Am J Resp Crit Care Med 2000; 162: $1851-1854$

24 Ferebee S H. Controlled chemoprophylaxis trials in tuberculosis - A general review. Adv Tuberc Res 1970; 18: 28-106

25 Sutherland I. Recent studies in the epidemiology of tuberculosis, based on the risk of being infected with tubercle bacilli. Adv Tuberc Res 1976; 19: 1-63

26 Neumann G. Aufgaben des Gesundheitsamtes bei der Tuberkulosebekämpfung. Öff Gesund-Wes 1985; 47: 98-100

27 Weis S E, Pogada J M, Yang Z et al. Transmission dynamics of tuberculosis in Tarrant County. Am J Respir Crit Care Med 2002; 166: 36-42

28 Small P M, Hopewell P C, Singh S P et al. The epidemiology of tuberculosis in San Francisco: a population-based study using conventional and molecular methods. N Engl J Med 1994; 330: 17031709 
29 Van Soolingen D, Borgdorff M W, de Haas P E et al. Molecular epidemiology of tuberculosis in The Netherlands: a nationwide survey from 1993 through 1997. J Infect Dis 1999; 180: 726-736

30 Alland D, Kalkut G E, Moss A R et al. Transmission of tuberculosis in New York City: an analysis by DNA fingerprinting and conventional epidemiologic methods. N Engl J Med 1994; 330: 1710-1716 31 Van Deutekom H, Gerritsen J J, van Soolingen D et al. A molecular epidemiological approach to studying the transmission of tuberculosis in Amsterdam. Clin Infect Dis 1997; 25: 1071-1077 32 Braden C R, Templeton G L, Cave M D et al. Interpretation of restriction fragment length polymorphism analysis in $M$. tuberculosis isolates from a state with a large rural population. $J$ Infect Dis 1997; 175: 1446-1452

33 Sebek M. DNA fingerprinting and contact investigation. Int J Tuberc Lung Dis 2000; 4: S45-S48

34 Seidler A, Diel R. Aspekte der beruflichen Übertragung der Tuberkulose im Lichte neuer molekularbiologischer Ansätze.. In: Nienhaus A, Brandenburg S, Teschler H, Hrsg. Tuberkulose als Berufskrankheit.. Landsberg: ecomed; 2003

35 Robert Koch-Institut .Bericht zur Epidemiologie der Tuberkulose in Deutschland für 2009.. Berlin; 2011

36 American Thoracic Society (ATS), Centers for Disease Control and Prevention (CDC), American Academy of Pediatrics and Infectious Disease Society of America .Control of tuberculosis in the United States. Am Rev Resp Dis 1992; 118: 1623-1633

37 British Thoracic and Tuberculosis Association .A study of a standardised contact procedure in tuberculosis. Tubercle 1978; 59: 245-259

38 Köhler H. Übertragung einer Tuberkulose auf dem Genitalwege. Zschr Urol 1973; 66: 207-209

39 Diel R, Meywald-Walter K, Gottschalk R et al. Ongoing outbreak of tuberculosis in a low-incidence community: a molecular-epidemiological evaluation. Int J Tuberc Lung Dis 2004; 8: 855-861

40 Bales S, Baumann H G, Schnitzler N. Kommentar zum Infektionsschutzgesetz - IfSG.. Köln: W. Kohlhammer; 2000

41 Erdle H. Das Infektionsschutzgesetz, Kommentar.. Landsberg/Lech: ecomed; 2000

42 Anonymus. Die Tätigkeit des Gesundheitsamtes bei der Tuberkulosefürsorge. VersR 1959; : 353-

355

43 Anonymus. Verordnung über den Schutz vor Schäden durch Röntgenstrahlen (Röntgenverordnung - RöV). BGBI I . vom 8.1.1987; : 114-133

44 Anonymus. Verordnung zur Änderung der Röntgenverordnung und anderer atomrechtlicher Verordnungen (RöV). BGBI I. vom 21. 6. 2002; : 1869ff

45 Deutsches Zentralkomitee zur Bekämpfung der Tuberkulose (DZK) .Das Strahlenrisiko bei

Röntgenuntersuchungen des Thorax. Pneumologie 2001; 55: 57-71

46 Kaufmann S HE. Die Immunantwort gegen Tuberkulose.. In: Konietzko N, Loddenkemper R, Hrsg. Tuberkulose.. Stuttgart: Thieme; 1999

47 Singh D, Sutton C, Woodcock A. Tuberculin test measurement - variability due to the time of reading. Chest 2002; 122: 1299-1301

48 Youssef E, Wooltorton E. Serious allergic reactions following tuberculin skin tests. CMAJ 2005; $173: 34$

49 Menzies D. Interpretation of repeated tuberculin tests. Boosting, conversion and reversion. Am J

Respir Crit Care Med 1999; 159: 15-21

50 Poulsen A. Some clinical features of tuberculosis. 1. Incubation period. Acta Tuberc Scand

1950; 24: 311-346

51 Deutsches Zentralkomitee zur Bekämpfung der Tuberkulose (DZK) .Richtlinien zur

Tuberkulindiagnostik. Dt Ärztebl 1996; 93: 1199-1201

52 Horsburgh Jr C R. Priorities for the treatment of latent tuberculosis infection in the United States. N Engl J Med 2004; 350: 2060-2079

53 Lange C, Schaberg T, Diel R et al. Aktueller Stand der Tuberkulosediagnostik. DMW 2006; 131: 341-347

54 Comstock G W. Identification of an effective vaccine against tuberculosis. Am Rev Respir Dis 1988; 138: 479-480

55 Tissot F, Zanetti G, Francioli P et al. Influence of Bacille Calmette-Guérin vaccination on size of tuberculin skin test reaction: to what size?. Clin Inf Dis 2005; 40: 211-217

56 Menzies D, Pai M, Comstock G. Meta-analysis: new tests for the diagnosis of latent tuberculosis infection: areas of uncertainty and recommendations for research. Ann Intern Med 2007; 146: 340-354 Erratum in: Ann Intern Med 2007; 146: 688

57 Mori T, Sakatani M, Yamagishi F et al. Specific detection of tuberculosis infection: an interferongamma-based assay using new antigens. Am J Respir Crit Care Med 2004; 170: 59-64

58 Diel R, Goletti D, Ferrara $G$ et al. Interferon-y release assays for the diagnosis of latent

Mycobacterium tuberculosis infection: a systematic review and meta-analysis. Eur Respir J 2011; 37: 88-99 
59 Simon K, Gutland M. Die Tuberkulinprobe in der Klinik - Dosierung und Wertung. Prax Klin Pneumol 1988; 42: 423-426

60 Cole S T, Brosch R, Parkhill J et al. Deciphering the biology of Mycobacterium tuberculosis from the complete genome sequence. Nature 1998; 393: 537-544 Erratum in: Nature 1998; 396: 190

61 Pai M, Kalantri S, Dheda K. New tools and emerging technologies for the diagnosis of tuberculosis: Part 1. Latent tuberculosis. Expert Rev Mol Diagn 2006; 6: 413-422

62 Anibarro L, Trigo M, Villaverde $C$ et al. Interferon- $y$ release assays in tuberculosis contacts: is there a window period?. Eur Respir J 2011; 37: 215-217

63 Lee S W, Oh D K, Lee S H et al. Time interval to conversion of interferon-\{gamma\} release assay after exposure to tuberculosis. Eur Respir J. 2010 Dec 9 [Epub ahead of print]

64 Diel R, Loddenkemper R, Nienhaus A. Evidence-based comparison of commercial interferongamma release assays for detecting active TB: a metaanalysis. Chest 2010; 137: 952-968 65 Sester M, Sotgiu G, Lange C et al. Interferon-y release assays for the diagnosis of active tuberculosis: a systematic review and meta-analysis. Eur Respir J 2011; 37: 100-111

66 Hoffmann M, Raven P. The use of Interferon-gamma Release assays in HIV-positive individuals. Eur Infect Dis 2010; 4: 23-29

67 Pai M, Zwerling A, Menzies D. Systematic review: T-cell based assays for the diagnosis of latent tuberculosis infection: an update. Ann Intern Med 2008; 149: 177-184

68 Bamford A R, Crook A M, Clark J E et al. Comparison of Interferon-gamma release assays and Tuberculin Skin Test in predicting active tuberculosis (TB) in children in the UK: a paediatric TB Network Study. Arch Dis Child 2010; 95: 180-186 [Epub 2009 Oct 8]

69 Bianchi L, Galli L, Moriondo $\mathrm{M}$ et al. Interferon-gamma release assay improves the diagnosis of tuberculosis in children. Pediatr Infect Dis J 2009; 28: 510-514

70 Connell T G, Ritz N, Paxton G A et al. A three-way comparison of tuberculin skin testing,

QuantiFERON-TB Gold and T-Spot.TB in children. PLos One 2008; 3: e2624

71 Cruz A T, Geltemeyer A M, Starke J R et al. Comparing the tuberculin skin test and T-SPOT.TB blood test in children. Pediatrics 2011; 127: e31-e38 [Epub 2010 Dec 6]

72 Detjen A K, Keil T, Roll S et al. Interferon-gamma release assays improve the diagnosis of tuberculosis and nontuberculous mycobacterial disease in children in a country with a low incidence of tuberculosis. Clin Infect Dis 2007; 45: 322-328

73 Kampmann B, Whittaker E, Williams A et al. Interferon-gamma release assays do not identify more children with active TB than TST. Eur Respir J 2009; 33: 1374-1382

74 Nicol M P, Davies M A, Wood K et al. Comparison of T-SPOT.TB assay and tuberculin skin test for the evaluation of young children at high risk for tuberculosis in a community setting. Pediatrics 2009; 123: 38-43

75 Bienek D R, Chang C K. Evaluation of an interferon-gamma release assay, T-SPOT.TB, in a population with a low prevalence of tuberculosis. Int J Tuberc Lung Dis 2009; 13: 1416-1421

76 Wang S H, Powell D A, Nagaraja $\mathrm{H}$ N et al. Evaluation of a modified interferon-gamma release assay for the diagnosis of latent tuberculosis infection in adult and paediatric populations that enables delayed processing. Scand J Infect Dis 2010; 42: 845-850

77 Aichelburg M C, Rieger A, Breitenecker F et al. Detection and prediction of active tuberculosis disease by a whole-blood interferon-gamma release assay in HIV-1-infected individuals. Clin Infect Dis 2009; 48: 954-962

78 Clark S A, Martin S L, Pozniak A et al. Tuberculosis antigen-specific immune responses can be detected using enzyme-linked immunospot technology in human immunodeficiency virus (HIV)-1 patients with advanced disease. Clin Exp Immunol 2007; 150: 238-244

79 Diel R, Loddenkemper R, Niemann S et al. Negative and positive predictive value of a whole-blood interferon-\{gamma\} release assay for dveloping active tuberculosis: An update. Am J Respir Crit Care Med 2011; 183: 88-95

80 Haldar $\mathrm{P}$, Thuraisingham $\mathrm{H}$, Hoskyns $\mathrm{W}$, Woltmann $\mathrm{G}$. Contact screening with single-step TIGRA testing and risk of active TB infection: The Leicester cohort analysis. Thorax 2009; 64 (Suppl. 4): A10 81 Kik S V, Franken W P, Mensen M et al. Predictive value for progression to tuberculosis by IGRA and TST in immigrant contacts. Eur Respir J 2010; 35: 1346-1353

82 Diel R, Schaberg T, Loddenkemper R et al. Enhanced cost-benefit analysis of strategies for LTBI screening and INH chemoprevention in Germany. Respir Med 2009; 103: 1838-1853

83 Diel R, Wrighton-Smith P, Zellweger J P. Cost-effectiveness of interferon-gamma release assay testing for the treatment of latent tuberculosis. Eur Respir J 2007; 30: 321-332

84 Rangaka M X, Wilkinson K, Seldon R et al. The effect of HIV-1 infection on T cell based and skin test detection of tuberculosis infection. Am J Respir Crit Care Med 2007; 175: 514-529

85 Liebeschuetz S, Bamber S, Ewer K et al. Diagnosis of tuberculosis in South African children with a T-cell-based assay: a prospective cohort study. Lancet 2004; 364: 2196-2039 
86 Passalent L, Khan K, Richardson R. Detecting latent tuberculosis infection in hemodialysis patients: A head-to-head comparison of the T-SPOT.TB test, tuberculin skin test, and an expert physician panel. Clin J Am Soc Nephr 2007; 2: 68-73

87 Diel R, Hauer B, Loddenkemper $R$ et al. Empfehlungen für das Tuberkulosescreening vor Gabe von TNF- $\alpha$-Inhibitoren bei rheumatischen Erkrankungen. Pneumologie 2009; 63: 329-334 und Z Rheumatol 2009; 68: 411 - 416

88 Meyer M, Clarke P, O'Regan A W. Utility of the lateral chest radiograph in the evaluation of patients with a positive tuberculin skin test result. Chest 2003; 124: 1824-1827

89 Tuberculosis coalition for technical assistance. International standards for tuberculosis care (ISTC). The Hague: Tuberculosis coalition for technical assistance.. 2006

90 National Institute for Clinical Excellence (NICE) .Tuberculosis. National clinical guideline for diagnosis, management, prevention, and control. March 2006 http://www.nice.org.uk Stand: 1. 4. 2011 91 Centers for Disease Control and Prevention .Guidelines for the investigation of contacts of persons with infectious tuberculosis: Recommendations from the National Tuberculosis Controllers Association and CDC. MMWR 2005; 54 (RR-15): 1-37

92 World Health Organization .Guidance for national tuberculosis programmes on the management of tuberculosis in children. Geneva; 2006 (WHO/HTM/TB/2006.371)

93 Magdorf K, Fehn T, Griese M et al. Tuberkulose und nichttuberkulöse mykobakterielle

Krankheiten.. In: Deutsche Gesellschaft für pädiatrische Infektiologie e. V. (DGPI), Hrsg. DGPI

Handbuch: Infektionen bei Kindern und Jugendlichen.. Stuttgart: Georg Thieme; 2009

94 American Thoracic Society .Targeted tuberculin testing and treatment of latent tuberculosis infection. MMWR Recomm Rep 2000; 49 (RR-6): 1-51

95 Schaberg T, Castell S, Dalhoff $\mathrm{K}$ et al. Empfehlungen zur medikamentösen Therapie der

Tuberkulose im Erwachsenen- und Kindesalter. Pneumologie 2011; [in Vorbereitung]

96 Nardell E A, Wallis R S. Here today - gone tomorrow: the case for transient acute tuberculosis infection. Am J Respir Crit Care Med 2006; 174: 734-735

97 Centers for Disease Control and Prevention .Updated guidelines for using interferon gamma release assays to detect Mycobacterium tuberculosis infection - United States, 2010. MMWR Recomm Rep 2010; 59 (RR-5): 1-25

98 Perry S, Parsonnet J. Commentary: H. pylori infection in early life and the problem of imperfect tests. Int J Epidemiol 2005; 34: 1356-1358

99 Perry S, Sanchez L, Yang S et al. Reproducibility of QuantiFERON-TB gold in-tube assay. Clin Vaccine Immunol 2008; 15: 425-432

100 Ewer K, Millington K A, Deeks J J et al. Dynamic antigen-specific T cell responses after pointsource exposure to Mycobacterium tuberculosis. Am J Respir Crit Care Med 2006; 174: 831-839

101 Friedman L N, Nash E R, Bryant $\mathrm{J}$ et al. High rate of negative results of tuberculin and QuantiFERON tests among individuals with a history of positive skin test results. Infect Control Hosp Epidemiol 2006; 27: 436-441

102 Shams H, Weis S E, Klucar P et al. Enzyme-linked immunospot and tuberculin skin testing to detect latent tuberculosis infection. Am J Respir Crit Care Med 2005; 172: 1161-1168

103 Loytved G. Umgebungsuntersuchungen in Schulen. Tuberkulintestung am Friedrich Dessauer Gymnasium Aschaffenburg. Vortragsmanuskript vom 17. 11. 2004.

104 RKI .Erfahrungsbericht: Tuberkulose in einer Klasse einer Mittelschule. Epid Bull 2004; 44: 377

105 RKI . Hinweise für Ärzte, Leitungen von Gemeinschaftseinrichtungen und Gesundheitsämter zur Wiederzulassung in Schulen und sonstigen Gemeinschaftseinrichtungen. Aktualisierte Fassung vom 25. Juli 2006. Erstveröffentlichung im Bundesgesundhbl - Gesundhforsch - Gesundhschutz 2001; 44: 830-841

106 RKI .Tuberkulose in großen Gemeinschaften. Beispiele der Handhabung von Umgebungsuntersuchungen. Epid Bull 2001; 41: 25-29

107 Verordnung zur Umsetzung von EG-Richtlinien über den Schutz der Beschäftigten gegen Gefährdung durch biologische Arbeitsstoffe bei der Arbeit (BioStoffV) vom 27. 01. 1999. BGBI I. 50-60 108 Kollecker S. Zur Frage der Anzeigepflicht von Ärzten bei der Tuberkulinkonversion.. In: Nienhaus A, Brandenburg S, Teschler H, Hrsg. Tuberkulose als Berufskrankheit.. Landsberg: ecomed; 2003

109 Nienhaus A, Loddenkemper R, Hauer B et al. Latente Tuberkulose-Infektionen im Gesundheitswesen - Evaluation des Interferon-y Release Assay. Pneumologie 2007; 61: 219-222 110 Torres Costa J, Sá R, Cardoso M J et al. Tuberculosis screening in Portuguese healthcare workers using the Tuberculin Skin Test and the Interferon-y release assay. Eur Resp J 2009; 34: 1423-1428

$111 \mathrm{MiQ}$.Mikrobiologisch-infektiologische Qualitätsstandards (MiQ) 5-Tuberkulose, Mykobakteriose.. München: Elsevier; 2010 
112 RKI .Zu einer ausgedehnten Tuberkulosehäufung im Wohn- und Arbeitsumfeld von Behinderten. Epid Bull 2004; 44: 378-379

113 Kendig N. Tuberculosis control in prisons. Int J Tuberc Lung Dis 1998; 2: S57-S63

114 World Health Organization .Tuberculosis and air travel. Guidelines for prevention and control. 3rd edition Geneva; 2008. (WHO/HTM/TB/2009.399)

$115 \mathrm{ECDC}$ technical report. Risk assessment guidelines for infectious diseases transmitted on aircraft. Stockholm; 2009

http://www.ecdc.europa.eu/en/publications/Publications/0906_TER_Risk_Assessment_Guidelines_for Infectious_Diseases_Transmitted_on_Aircraft.pdf Stand: 1. 4. 2011

$\overline{1} 16$ Gronauer W, Pregler M, Wolf P. Bemerkenswerte Tuberkulose-Kleinepidemien 2001/2002 in zwei bayerischen Regierungsbezirken. Pneumologie 2004; 58: 9-16

117 Hauer B, Kunitz F, Sagebiel D et al. Untersuchungen zur Tuberkulose in Deutschland: Molekulare Epidemiologie, Resistenzsituation und Behandlung (überarbeiteter Abschlussbericht zur DZK-Studie). Berlin: DZK; 2006

118 Malakmadze N, González I M, Oemig T et al. Unsuspected recent transmission of tuberculosis among high-risk groups: implications of universal tuberculosis genotyping in its detection. Clin Infect Dis 2005; 40 : $366-373$

119 De Vries G, van Hest R A, Burdo C C et al. A Mycobacterium tuberculosis cluster demonstrating the use of genotyping in urban tuberculosis control. BMC Infect Dis 2009; 9: 151 
Tabellen und Abbildungen

Tabelle 1 Soziale und organisatorische Probleme der Indexfälle und Kontakte zu den zuständigen Behörden.

\begin{tabular}{|c|c|c|}
\hline Indexfall & Probleme & Kontakt zu Behörde \\
\hline Asylbewerber & $\begin{array}{l}\text { Verlängerung der Aufenthaltsgenehmigung } \\
\text { zur Durchührung einer korrekten } \\
\text { antituberkulotischen Behandlung } \\
\text { Verständigungsschwierigkeiten }\end{array}$ & $\begin{array}{l}\text { Ausländerbehörde, ärztlicher } \\
\text { Dienst der zentralen } \\
\text { Gemeinschaftsunterkunft } \\
\text { Dolmetscher }\end{array}$ \\
\hline $\begin{array}{l}\text { Migranten mit } \\
\text { ungeklärtem } \\
\text { Aufenthaltsstatus }\end{array}$ & $\begin{array}{l}\text { illegaler Aufenthalt, keine } \\
\text { Krankenversicherung } \\
\text { Verständigungsschwierigkeiten }\end{array}$ & $\begin{array}{l}\text { Aufenthaltsfeststellung durch die } \\
\text { Ausländerbehörde } \\
\text { Dolmetscher }\end{array}$ \\
\hline Spätaussiedler & $\begin{array}{l}\text { bei nicht deutschstämmigen Ehepartnern } \\
\text { Unklarheiten über Krankenversicherung } \\
\text { Verständigungsschwierigkeiten }\end{array}$ & $\begin{array}{l}\text { Sozialamt, ggf. andere Behörden } \\
\text { Dolmetscher }\end{array}$ \\
\hline $\begin{array}{l}\text { Obdachloser } \\
\text { Häftling unmittelbar } \\
\text { nach Entlassung aus } \\
\text { JVA }\end{array}$ & $\begin{array}{l}\text { Keine Unterkunft, keine } \\
\text { Krankenversicherung }\end{array}$ & $\begin{array}{l}\text { Wohnungsamt, karitative } \\
\text { Organisationen, Sozialamt }\end{array}$ \\
\hline $\begin{array}{l}\text { Psychisch bzw. geistig } \\
\text { Kranker }\end{array}$ & $\begin{array}{l}\text { Gesundheitsfürsorge } \\
\text { A.ufenthalt }\end{array}$ & $\begin{array}{l}\text { Gericht } \\
\text { Betreuungsstelle }\end{array}$ \\
\hline $\begin{array}{l}\text { Erkrankter in } \\
\text { finanzieller Notlage }\end{array}$ & $\begin{array}{l}\text { Wohnungsbeschaffung, ggf. } \\
\text { Wohnraumsanierung }\end{array}$ & $\begin{array}{l}\text { Sozialamt, karitative } \\
\text { Organisationen }\end{array}$ \\
\hline
\end{tabular}

Tabelle 2 Mögliche Ursachen für einen falsch-negativen Tuberkulin-Hauttest (modifiziert nach [53]).

- Höheres Lebensalter ( $\geq 50$ Jahre)

- Zelluläre Immundefekte (z. B. HIV-Infektion, AIDS, lymphatische Systemerkrankungen)

- Akute oder kurz zurückliegende schwere Virusinfektionen (z. B. Masern, Mumps, Röteln, Influenza)

- Lebendimpfungen innerhalb der letzten 6 Wochen

- Schwere konsumierende Erkrankungen (z. B. Malignome)

- Systemische Kortikoidtherapie oder Behandlung mit Immunsuppressiva bzw. TNF-a-Inhibitoren

- Fulminante tuberkulöse Erkrankung (z. B. Miliartuberkulose)

- Sarkoidose

- Applikationsfehler (unvollständige oder subkutane Tuberkulininjektion)

- Ablesefehler (zu früh oder zu spät) 
Tabelle 3 Vergleich der kommerziellen IFN- $\mathrm{Y}$-Testverfahren[6].

\begin{tabular}{|c|c|c|}
\hline Name & $\begin{array}{l}\text { QuantiFERON-Tb } \\
\text { Gold In-Tube }\end{array}$ & T-spot.TB Test \\
\hline Hersteller & Cellestis & Oxford Immunotec \\
\hline Testmedium & Vollblut & PBMC \\
\hline Antigene & $\begin{array}{l}\text { In-vitro-Stimulation mit ESAT- } 6 \text {, } \\
\text { CFP-10 und TB } 7.7 \text { im } \\
\text { beschichteten Röhrchen }\end{array}$ & $\begin{array}{l}\text { In-vitro-Stimulation von } \\
\text { isolierten Lymphozyten mit } \\
\text { ESAT- } 6 \text {, CFP-10 }\end{array}$ \\
\hline Messmethode & ELISA & ELISPOT \\
\hline gemessene Zielgröße & $\begin{array}{l}\text { Konzentration von sezerniertem } \\
\text { IFN- } \mathrm{y}(\mathrm{IU} / \mathrm{ml})\end{array}$ & $\begin{array}{l}\text { IFN-V produzierende T-Zellen } \\
\left({ }_{N} \text { Spots }{ }^{N} \text { pro } 250000 \text { Zellen }\right.\end{array}$ \\
\hline benötigtes Blutuolumen & $3 \mathrm{ml}$ & $\begin{array}{l}\text { Erwachsene und Kinder } \geq 10 \\
\text { Jahren: } 8 \mathrm{ml} \\
\text { Kinder } 2-9 \text { Jahre: } 4 \mathrm{ml} \\
\text { Kinder bis zu } 2 \text { Jahren: } 2 \mathrm{ml} \\
\text { Immunsupprimierte: } 16 \mathrm{ml}\end{array}$ \\
\hline Inkubation & $16-24$ Std, bei $37^{\circ} \mathrm{C}$ & $\begin{array}{l}16-20 \text { Std. bei } 37 \circ \mathrm{C} \text { (mit } 5 \\
\left.\% \mathrm{CO}_{2}\right)\end{array}$ \\
\hline $\begin{array}{l}\text { Zeitfenster nach } \\
\text { Blutentnahme bis zur } \\
\text { Weiterverarbeitung im } \\
\text { Labor }\end{array}$ & $\begin{array}{l}\text { Lagerung der } \\
\text { Blutentnahmeröhrchen für bis zu } \\
16 \text { Std. nach Blutentnahme bei } \\
\text { Raumtemperatur vor der } \\
\text { Inkubation }\end{array}$ & $\begin{array}{l}\text { max. } 8 \text { Std. bei } \\
\text { Raumtemperatur* }\end{array}$ \\
\hline Test gilt als positiv, wenn & $\begin{array}{l}\text { (TB Ag - Negativkontrolle) } こ 0,35 \\
\text { IU/ml (Konzentration IFN-V) und } \\
\text { (TB Ag - Negativkontrolle) } \succeq 25 \\
\text { \% der Negativkontrolle }\end{array}$ & $\begin{array}{l}\text { Negatiukontrolle }<5 \text { Spots } \\
\text { und Panel A (CFP-10) oder } \\
\text { Panel B (ESAT-6) - Nil } 66 \\
\text { Spots pro } 250000 \text { Zellen } \\
\text { Panel A oder Panel B - Nil = } \\
5,6,7 \text { Spots gilt als } \\
\text { Graubereich: } \\
\text { Testwiederholung mit neuer } \\
\text { Probe empfohlen }\end{array}$ \\
\hline $\begin{array}{l}\text { Test gilt als nicht } \\
\text { interpretierbar } \\
\text { ( }{ }_{\text {indeterminant }} \text { ), wenn }\end{array}$ & $\begin{array}{l}\text { Resultat pos. Kontrolle minus } \\
\text { neg. Kontrolle }<0,5 \mathrm{IU} / \mathrm{ml} \text { und } \\
\text { Resultat TB-Antigen minus neg. } \\
\text { Kontrolle }<0,35 \mathrm{IU} / \mathrm{ml} \\
\text { oder } \\
\text { Resultat pos. Kontrolle minus } \\
\text { neg. Kontrolle }<0,5 \mathrm{IU} / \mathrm{ml} \text { und } \\
\text { Differenz zwischen TB-Antigen } \\
\text { und neg. Kontrolle }<25 \% \\
\text { oder }\end{array}$ & $\begin{array}{l}\text { pos. Kontrolle }<20 \text { Spots } \\
\text { oder } \\
\text { neg. Kontrolle }>10 \text { Spots }\end{array}$ \\
\hline
\end{tabular}

* nach Herstellerangaben bei zusätzlicher Anwendung von $X$ tend ${ }^{\circledR}$ bis zu 32 Std. 
Tabelle 4 Sensitivität von THT und IFN- $y$-Tests bei Kindertuberkulose (Stand 1. 2. 2011).

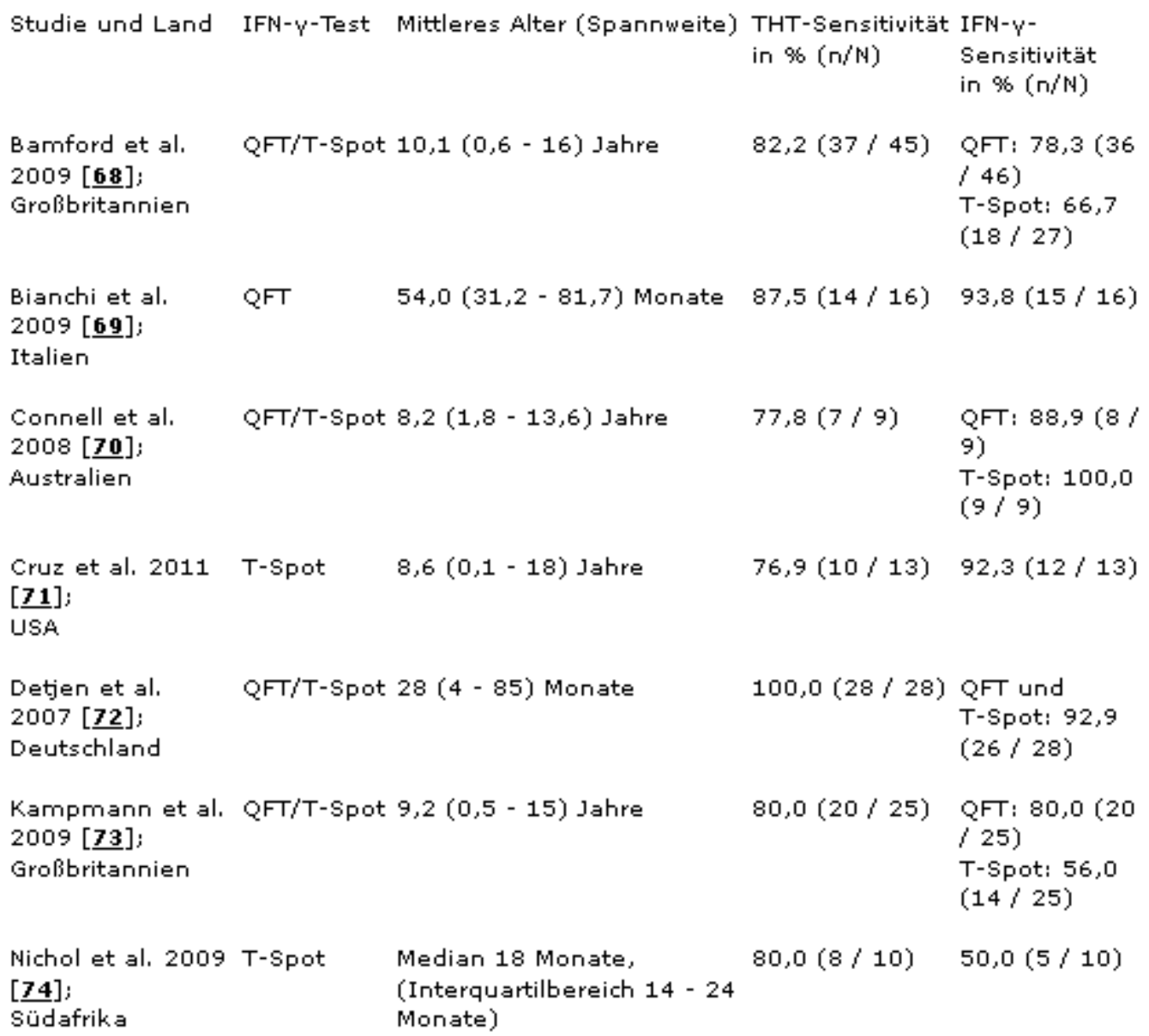

Gemittelte Sensitivität:

TST: 124 / 146; 84,9\% [95\% KI 78,1\% - 90,3\%]

QFT: $105 / 124 ; 84,6 \%[95 \% \mathrm{KI} 77,1 \%-90,5 \%]$

T-Spot: 84 / 112; 75,0\% [95\% KI 65,9\% - 82,7\%]

Tabelle 5 Erwarteter Anteil an Konversionen bzw. Reversionen beim Nachtesten negativer bzw. positiver IFN- $\gamma$-Ergebnisse am Beispiel des QFT (Sensitivität 84,5\%, Spezifität $99 \%$ ), modifiziert nach [99].

\begin{tabular}{lllll}
$\begin{array}{l}\text { Infektions- } \\
\text { Prävalenz (\%) }\end{array}$ & $\begin{array}{l}\text { PPV } \\
(\%)\end{array}$ & $\begin{array}{l}\text { NPV } \\
(\%)\end{array}$ & $\begin{array}{l}\text { Erwarteter Anteil an } \\
\text { Konversionen (\%) }\end{array}$ & $\begin{array}{l}\text { Erwarteter Anteil an } \\
\text { Reversionen (\%) }\end{array}$ \\
\hline 1 & 46,0 & 99,8 & 1,1 & 60,5 \\
\hline 5 & 81,6 & 99,2 & 1,7 & 30,8 \\
\hline 10 & 90,4 & 98,3 & 2,4 & 23,5 \\
\hline 20 & 95,5 & 96,2 & 4,1 & 19,3 \\
\hline 50 & 98,8 & 86,5 & 12,3 & 15,5
\end{tabular}


Abbildung 1 Die beiden Richtungen der Umgebungsuntersuchung: zentripetal bzw. zentrifugal.

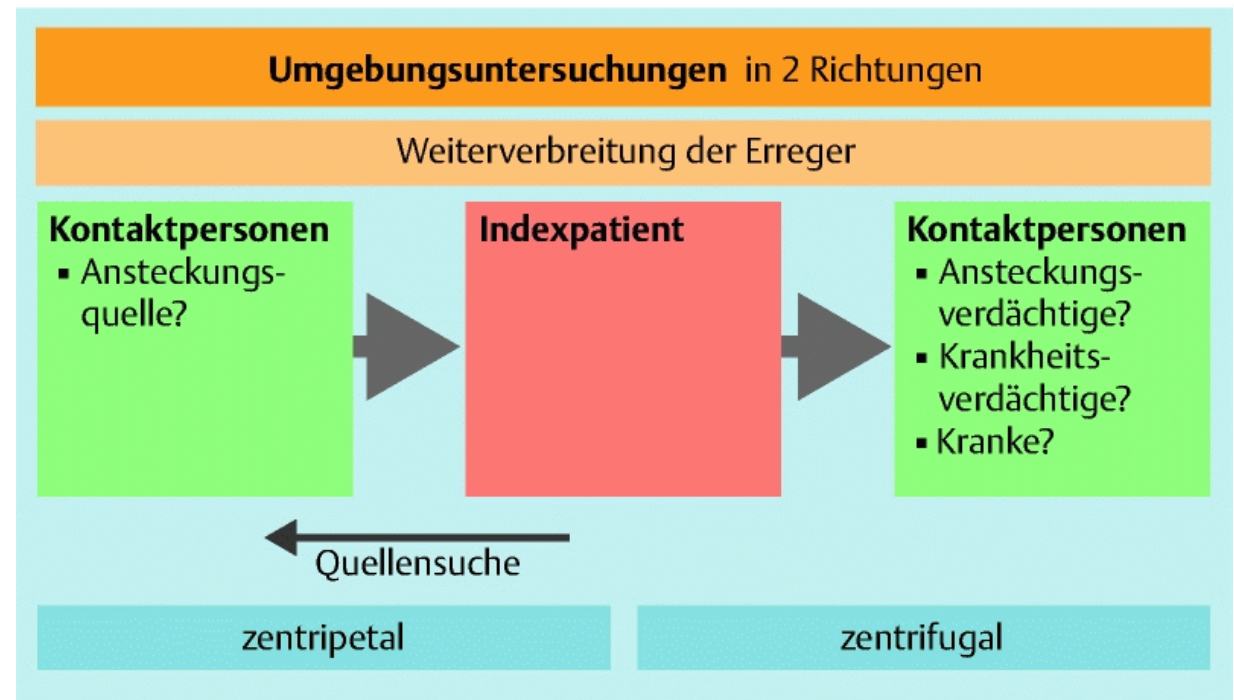

Abbildung 2 Flussdiagramm zur Umgebungsuntersuchung für enge Kontaktpersonen eines TBIndexfalles: Kinder unter 5 Jahren.

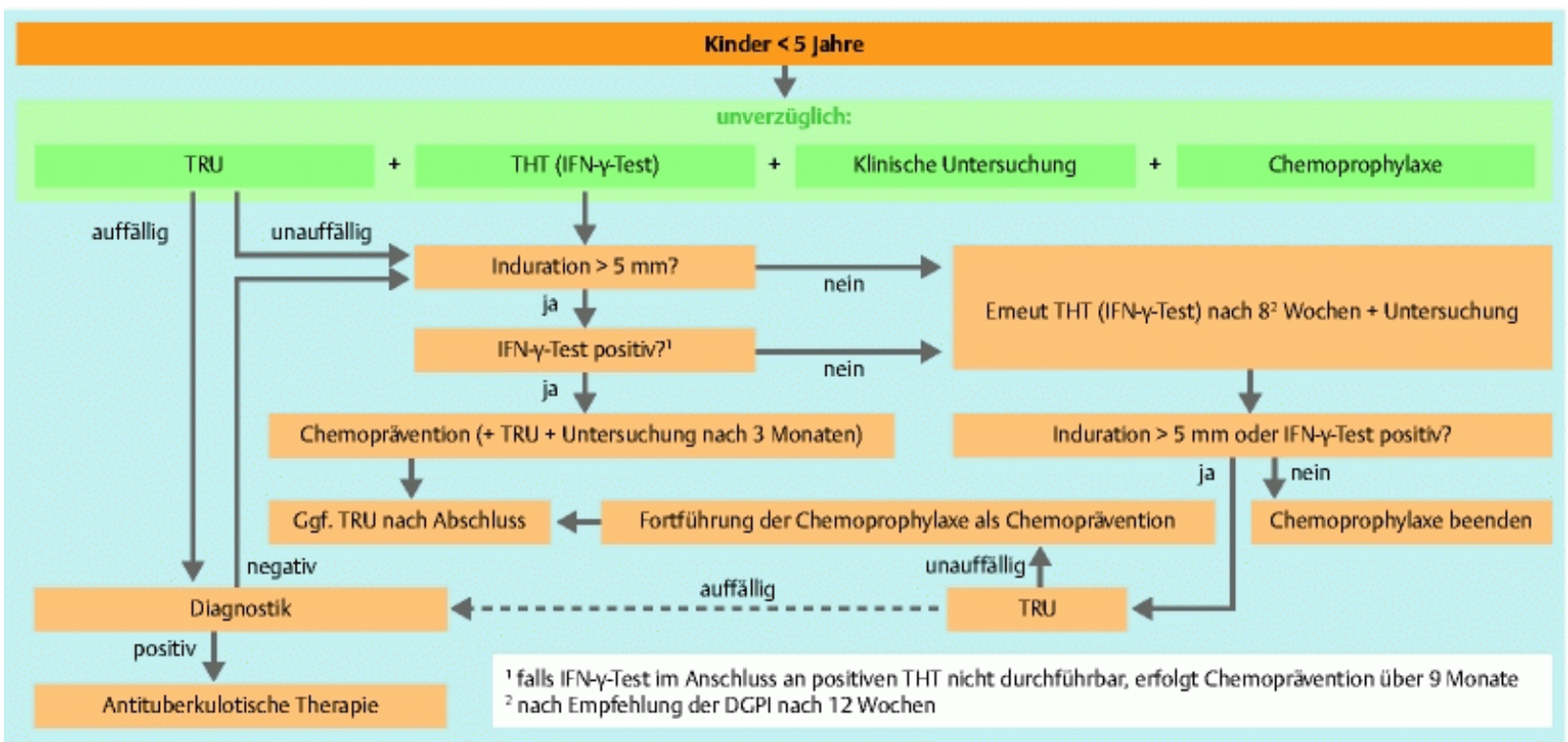


Abbildung 3 Flussdiagramm zur Umgebungsuntersuchung für enge Kontaktpersonen eines TBIndexfalles: Kinder 5 bis $<15$ Jahre.

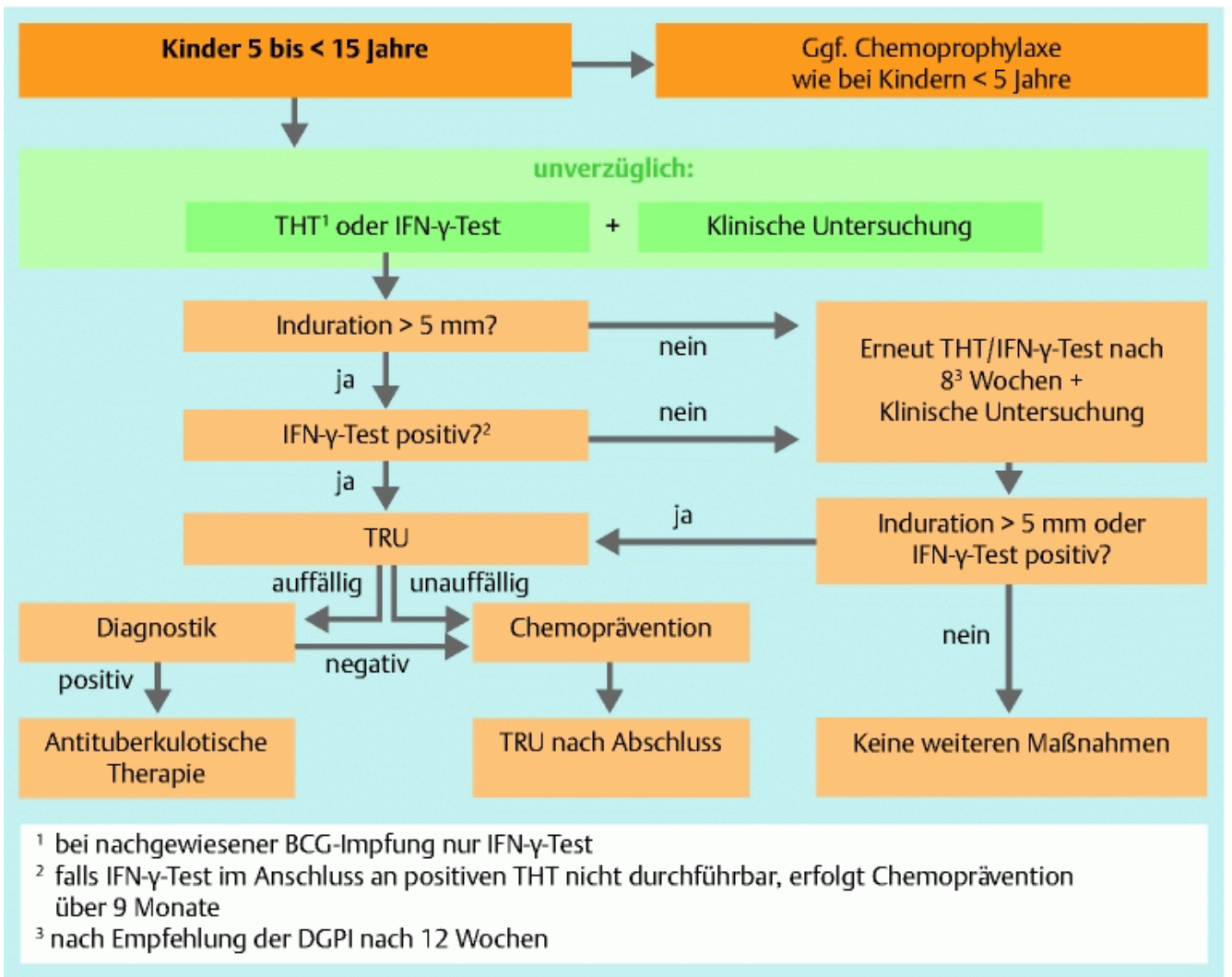

Abbildung 4 Flussdiagramm zur Umgebungsuntersuchung für enge Kontaktpersonen eines TBIndexfalles: Jugendliche und Erwachsene ab 15 Jahren.

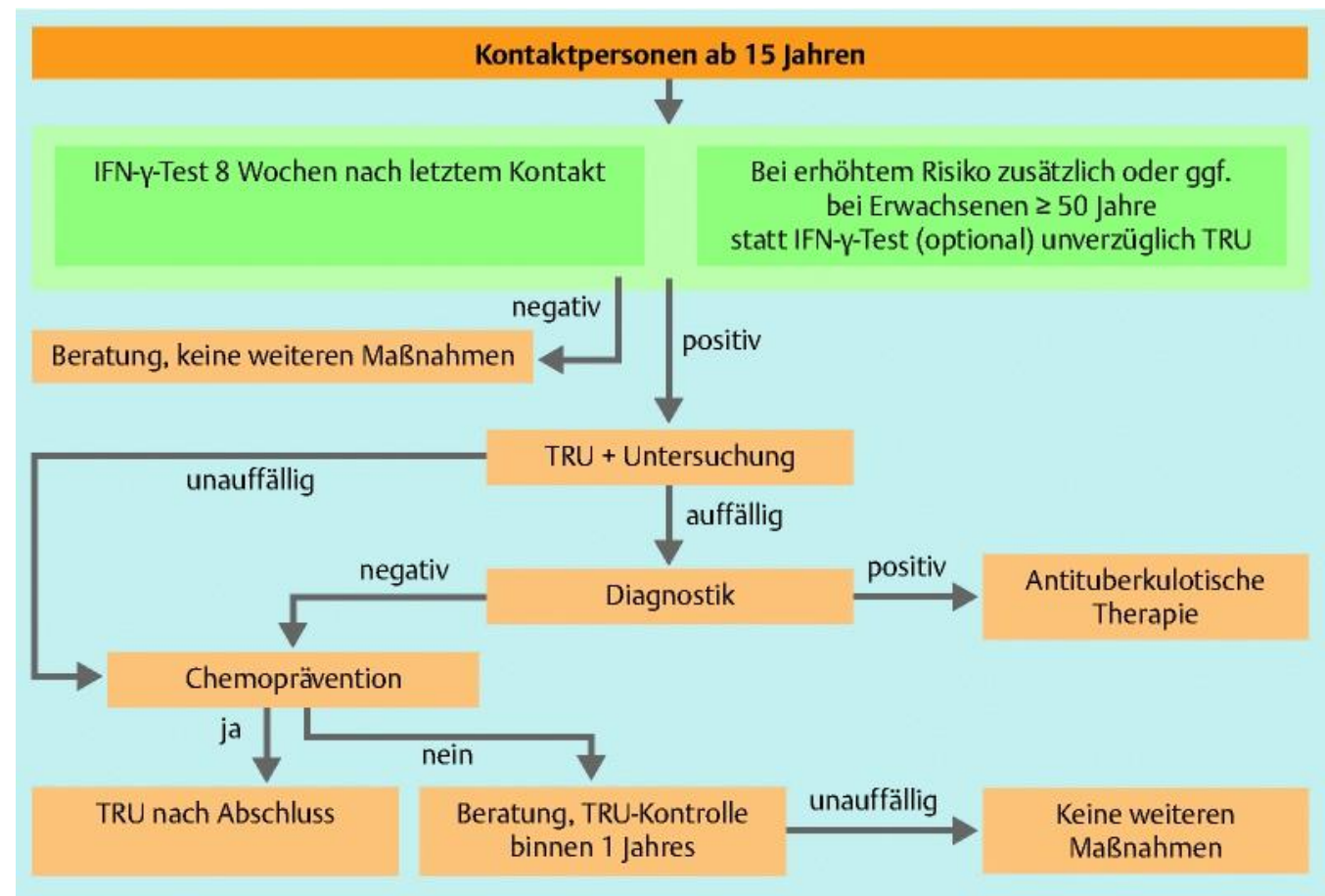

